\title{
Teaching intermediate-level technical and musical skills through the study and performance of selected piano duos
}

\author{
Yunn Bing Christine Tan \\ West Virginia University
}

Follow this and additional works at: https://researchrepository.wvu.edu/etd

\section{Recommended Citation}

Tan, Yunn Bing Christine, "Teaching intermediate-level technical and musical skills through the study and performance of selected piano duos" (2007). Graduate Theses, Dissertations, and Problem Reports.

4341.

https://researchrepository.wvu.edu/etd/4341

This Dissertation is protected by copyright and/or related rights. It has been brought to you by the The Research Repository @ WVU with permission from the rights-holder(s). You are free to use this Dissertation in any way that is permitted by the copyright and related rights legislation that applies to your use. For other uses you must obtain permission from the rights-holder(s) directly, unless additional rights are indicated by a Creative Commons license in the record and/ or on the work itself. This Dissertation has been accepted for inclusion in WVU Graduate Theses, Dissertations, and Problem Reports collection by an authorized administrator of The Research Repository @ WVU.

For more information, please contact researchrepository@mail.wvu.edu. 
TEACHING INTERMEDIATE-LEVEL TECHNICAL AND MUSICAL SKILLS THROUGH THE STUDY AND PERFORMANCE OF SELECTED PIANO DUOS

\author{
Yunn Bing “Christine” Tan
}

A Doctoral Research Project submitted to

The College of Creative Arts

at

West Virginia University in partial fulfillment of the requirements

for the degree of Doctor of Musical Arts

in

Piano Performance

Christine Kefferstan, D.M.A., Chair

Keith Jackson, D.M.A.

Ping Lee, Ph.D.

Connie Arrau Sturm, Ph.D., research advisor

David Taddie, Ph.D.

Division of Music

Morgantown, West Virginia

2007

Keywords: Duo, Duet, Intermediate repertoire, Two pianos, Two-Piano, Multiple pianos 


\section{ABSTRACT \\ Teaching Intermediate-Level Technical and Musical Skills Through the Study and Performance of Selected Piano Duos}

\section{Yunn Bing “Christine” Tan}

The study and performance of ensemble repertoire can provide benefits at all levels of music study. Playing piano duos (two people at two pianos) is enjoyable for young students and can help maintain their interest in playing the piano. Furthermore, skills acquired in duo-piano playing, such as communication, coordination, and balance can not only be transferred to solo and/or duet performance, but can also develop a foundation for performing other types of chamber music, thus preparing young students to accompany other instrumentalists or vocalists or even a choir in the near future.

This study provides a pedagogical guide that presents suggestions for teaching intermediate-level technical, musical skills, and collaborative skills through the study of selected intermediate-level piano duos from various musical periods. Specific technical and musical skills that students can hone from the study of this repertoire (including rhythm, phrasing and articulation, dynamics, musical style, balance, pedaling, and coordination of the ensemble) are discussed from the pedagogical standpoint. 


\section{TABLE OF CONTENTS}

\section{CHAPTER}

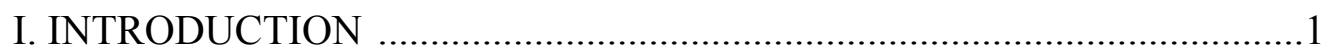

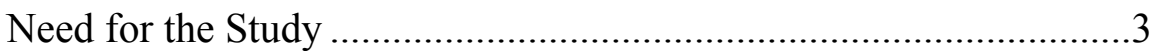

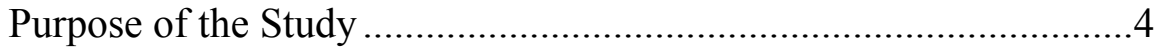

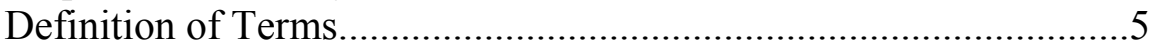

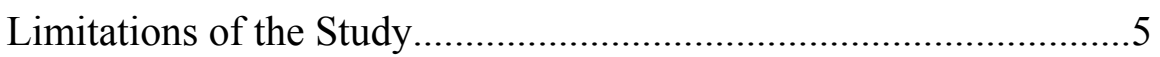

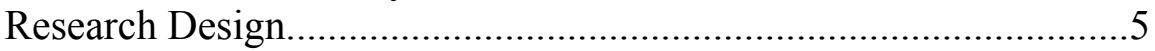

II. REVIEW OF RELATED LITERATURE ………………………………....

Sources that Consist Mainly of Databases of Literature......................

Sources that Consist Mainly of Analyses and Performance

Suggestions for Selected Pieces ................................................12

Sources that are Primarily Historical Overviews.............................18

Sources that Study Ensemble Playing.................................................21

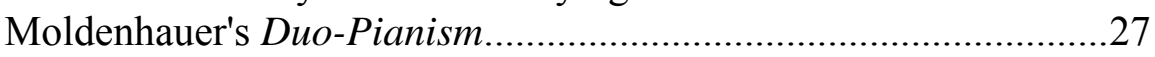

\section{SUGGESTIONS FOR TEACHING TECHNICAL AND} MUSICAL SKILLS THROUGH STUDY OF SELECTED

PIANO DUOS...................................................... 31

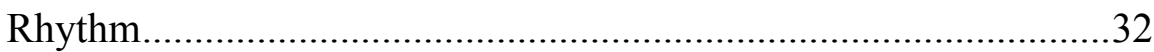

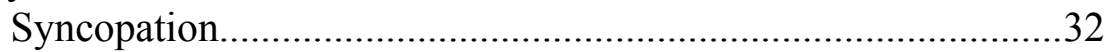

Cross rhythm .................................................................

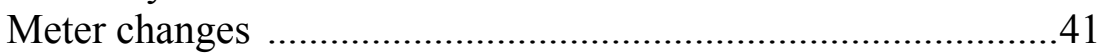

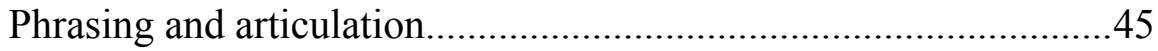

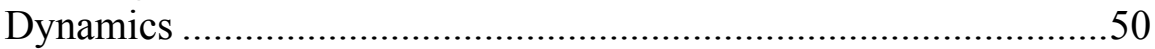

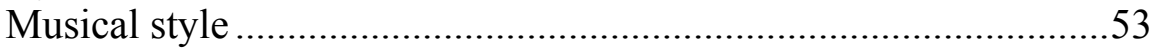

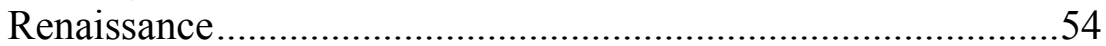

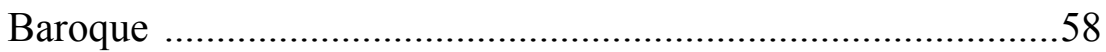

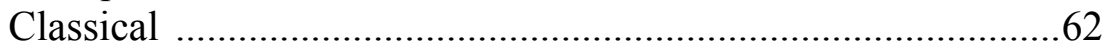

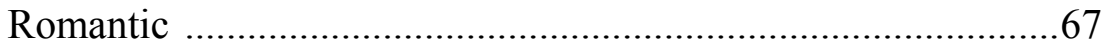

Twentieth-century ……………………………………….......

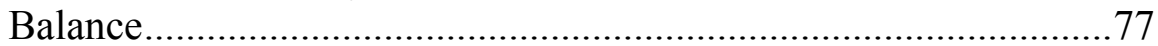

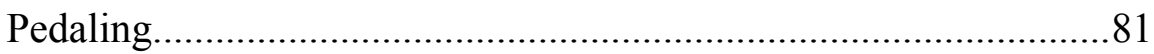

Coordination of the ensemble (watching, signaling, breathing) .......84 
IV. SUMMARY, CONCLUSIONS, AND RECOMMENDATIONS FOR

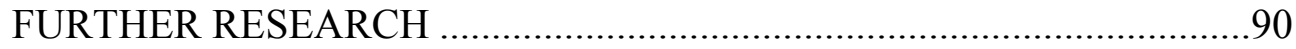

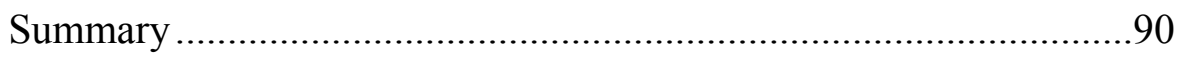

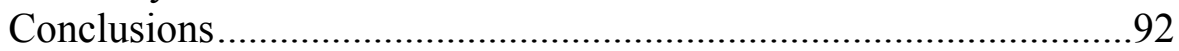

Recommendations for Further Research...........................................94

APPENDIX A: TITLES, COMPOSERS AND PUBLICATION

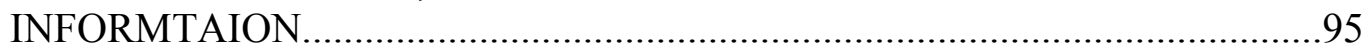

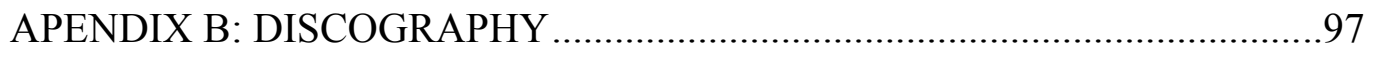

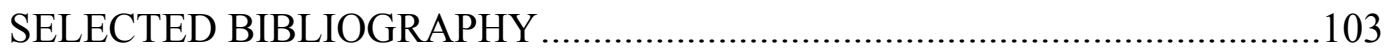




\section{CHAPTER I}

\section{INTRODUCTION}

Most piano students focus their time and attention on the study and performance of solo literature. Without adequate opportunities to learn ensemble skills, they may eventually have a difficult time working with other musicians when they need to play chamber music. Thus, ensemble music should not be overlooked. In fact, ensemble playing not only offers joy and fun in music making, but it also can provide benefits at all levels. Even though pianists can find repertoire for numerous combinations of ensembles with other instrumentalists or vocalists, playing piano duets (two people at one piano) and duos (two people at two pianos) is usually the preferred way to begin ensemble experiences. When both performers play the same instrument or type of instrument, the performance techniques are the same, and thus both players have more understanding of the musical and performance elements as well as the performance medium.

Historically, playing piano duets (one piano, four hands) has been more popular than playing piano duos (two pianos, four hands), because owning one piano is more affordable and also takes up less space than owning two pianos. Consequently, more original compositions have been written for piano duet than for piano duo. But, composers in the twentieth century began to compose much more duo-piano music. According to Chikako Sloan, there are several possible reasons for this growth. Sloan observed that pianists who cannot maintain a career as a soloist may begin to look for a 
new direction and may choose duo-piano performance. Sloan also noted that hearing duopiano performances is a new experience for audiences, and captures their attention with its dramatic style and uniqueness. ${ }^{1}$

While playing piano duets and playing piano duos may seem quite similar, there are significant differences in both the repertoire and the performance techniques for each medium. Sitting close to one's duet partner allows for far more intimate communication of musical ideas. In order for one pianist to be able to pedal for his partner, he must literally know his partner's every move. The physical intimacy of the performance medium and the musical intimacy of a smaller overall sound (compared to performance on two instruments) have inspired the composition of repertoire that is more personal more akin to chamber music than to orchestral music. For example, Schubert was certainly one of the greatest and most prolific piano duet composers of all time; however, even though he wrote a lot of duet pieces, he did not write any pieces for piano duo. Considering the large number of Lied that he composed, one might conclude that he was attracted to piano ensemble music that is more personal. On the other hand, piano duo music is more gigantic, grand, and showy in nature. Two pianos playing together create a bigger, more orchestral effect and a different timbre and tone color. Given the grand scale of duo-piano performance, it is not surprising to note that Liszt composed and arranged several works for two pianos (for four hands as well as for eight hands). According to the legendary duo team, Josef and Rosina Lhévinne, performing at two pianos is much more interesting and more enjoyable than performing with four hands at one piano. They felt

\footnotetext{
${ }^{1}$ Chikako Sloan, "Comparison of Duo-piano Performance and Solo-piano performance" (M.M. thesis, The Ball State University, 1986), 17.
} 
that duo music sounded much richer and that both players have greater freedom to draw upon resources in the bass, treble, and pedal. ${ }^{2}$

Despite the differences among the solo piano, piano duet, and piano duo mediums, much of the knowledge and skills a student learns in one of these mediums can be transferred to the other mediums. For all these types of performance, students need to develop the same piano technique. Furthermore, skills acquired in duo-piano playing, such as communication, coordination, and balance can not only be transferred to solo and/or duet performance, but can also develop a foundation for performing other types of chamber music, thus preparing young students to accompany other instrumentalists or vocalists or even a choir in the near future. Therefore, all piano students (elementary, intermediate, and advanced) can benefit from studying and performing duo-piano repertoire.

\section{Need for the Study}

Ideally, piano teachers should be familiar with a large amount of duo-piano repertoire at all levels of advancement from different musical periods. Unfortunately, most sources reviewed for this study focus on analyzing advanced-level repertoire for piano duo. Analyses and performance guidelines for intermediate-level duo-piano music are much more difficult to find. Some studies consist of only a list of intermediate-level duo pieces. But, no studies were found that related intermediate-level duo music to the development of intermediate-level technical and musical skills.

\footnotetext{
2 Joseph Lhévinne and Rosina Lhévinne, "Four Hands that Play as Two...," Etude 51 (December 1933): 809 .
} 


\section{Purpose of the Study}

The intermediate level of piano study is usually described as a time of transition for piano students, after they have completed elementary methods books and before they are ready to begin study of more difficult standard repertoire. Frequently, intermediate piano students lose interest in learning more difficult music and eventually discontinue piano lessons. Having them play some duo music with their friends is a good way to keep their interest in continuing to take piano lessons. In addition, playing duo music not only can help develop and reinforce some solo playing techniques, such as listening carefully to melodic lines, phrasing, and breathing, but can also help establish some daily life skills that everybody should have such as personal responsibility, time management, selfdiscipline, objectivity, compromise and communication with peers. When selecting appropriate duo music, it is the teacher's responsibility to consider both students' weaknesses and strengths, and to assign them pieces that will further develop their performance ability.

The purpose of this study is to identify and discuss piano duos from various musical periods that can help intermediate piano students develop technical skills and musical knowledge related to the following areas of study:

1. rhythm

2. phrasing and articulation

3. dynamics

4. musical style

5. balance (between pianos, and/or within each piano part)

6. pedaling

7. coordination of the ensemble (watching, signaling, breathing) 
At least one duo-piano piece has been selected to illustrate and discuss the teaching of each technical and musical skill listed above. Only repertoire by recognized composers has been selected.

\section{Definition of Terms}

1. Duo-piano repertoire - This term is used to refer to compositions for two people at two pianos. In contrast, the term "piano duet repertoire" refers to compositions that two people play at one piano.

2. Intermediate-level - A student is considered to be at the intermediate level of piano study if he has the requisite musical and technical skills to play pieces such as the following: J. S. Bach's Two-part Inventions or Chopin's Waltz in B minor Op. 69, No. 2 or Debussy's Children's Corner suite.

\section{Limitations of the Study}

The scope of this study is limited in the following ways:

1. Only original two-piano, four-hand compositions are included.

2. Only published, intermediate-level repertoire is discussed.

3. No exercises or pieces whose main value is pedagogical (e.g., "teaching pieces" from piano method books) are included.

\section{$\underline{\text { Research Design }}$}

This study consists of four chapters. Chapter I consists of a brief introduction and a statement of the purpose of study. Chapter II presents a review of related literature. 
Chapter III provides discussion, guidelines, suggestions, and teaching strategies for teaching specific intermediate-level technical and musical skills through the study of specific duo-piano pieces. Finally, Chapter IV presents a summary and conclusions and offers recommendations for further research. 


\section{CHAPTER II \\ REVIEW OF RELATED LITERATURE}

Duo repertoire has been studied by many authors and researchers over the past fifty years. Some authors (e.g., Gary Keith McRoberts, James Friskin and Irwin Freundlich, Frederic Ming Chang and Albert Faurot, Carolyn Maxwell, and Howard Ferguson) have compiled lists or databases of duo-piano pieces, and provided very general descriptions for those pieces. Other authors (e.g., Ruth A. Neville, Eulalie Wilson Jeter, and Sister St. Cecilia Cutting) have focused primarily on a few advanced piano duos (mostly twentieth-century repertoire) and have provided more in-depth theoretical analyses and performance suggestions. Some authors (e.g., Margaret W. McCarthy, William Crandall Leech, and Walden Hughes) have centered their attention on the historical development of duo-piano literature and duo-piano teams. Finally, a few authors (e.g., Pierre Luboshutz and Genia Nemenoff, Dorothy Bridenthal, Pauline Venable Turrill, Clyde Duncan, Josef and Rosina Lhévinne, and Chikako Sloan) have concentrated their studies on ensemble performance. Only one author, Hans Moldenhauer in his dissertation, Duo-Pianism, has researched all of the areas listed above.

The sources reviewed in this chapter will be discussed in the following order: (1) those that consist mainly of databases of the literature; (2) those that consist mainly of analyses and performance suggestions for selected pieces; (3) those that are primarily historical overviews; (4) those that study ensemble playing, and 5) Moldenhauer's 
comprehensive dissertation covering all of these aspects of duo-piano performance and literature. The research reviewed includes books, dissertations, theses and articles.

\section{Sources that Consist Mainly of Databases of Literature}

Five studies were reviewed which outlined two-piano literature in catalogues or databases. Only one of these studies, that by Gary Keith McRoberts, focused on contemporary duo-piano pieces. The other four studies covered the duo repertoire from the sixteenth to the twentieth century. All of these studies are arranged alphabetically by the composer's name and all include a brief description of the piece as well as the publisher. Other information usually supplied includes the following: 1) level of difficulty (all sources except James Friskin and Irwin Freundlich), 2) date of composition (all sources except Friskin and Freundlich), and 3) additional repertoire by the same composer (all sources except McRoberts).

In 1973, McRoberts compiled an annotated catalog of original two-piano literature composed between the years of 1950 and $1970 .^{3}$ By looking at these dates, one may think this repertoire illustrates only stylistic features of the twentieth century; however, the compositional techniques used in these pieces range from traditional “classical” to "avant-garde." "While complete analyses of each composition were not included, the author did provide the information discussed above as well as composer country of origin, availability, number of movements, duration, and pagination. ${ }^{5}$

\footnotetext{
${ }^{3}$ Gary Keith McRoberts, “An Annotated Catalog of Original Two-Piano Literature 1950-1970” (M. A. Thesis, California State University at Long Beach, 1973), p. 1.

${ }^{4}$ Ibid., 1.

${ }^{5}$ Ibid., 4.
} 
In 1954, James Friskin and Irwin Freundlich identified and discussed the major keyboard literature (including solo works, works for four hands, and music for piano and orchestra) in their book entitled Music for the Piano: A Handbook of Concert and Teaching Material from 1580 to $1952 .^{6}$ This book is divided into five parts. The authors began their discussion with the solo repertoire. The first part focuses on early keyboard music before the advent of the pianoforte, followed by pianoforte music from Haydn to the early twentieth century in part two. Then, the third part focuses on piano music of the twentieth century, including compositions from Europe, Israel, England, the United States, and Latin America. Part four, "Original Works for Four Hands", is divided into two sections: music for one piano, four hands; and music for two pianos, four hands. Part five in the book focuses on music for piano and orchestra. ${ }^{7}$

Friskin and Freundlich claimed that the experience of playing four-hand music requires "not only the basic give and take required of all good chamber music performances but, in addition, it calls for the development of a sympathetic pianism in achieving a well-integrated balance of sound between "primo" and "secundo" parts." 8

In 1983, Carolyn Maxwell compiled a notebook to evaluate ensemble piano literature, and offer suggestions for teaching and playing each piece. ${ }^{9}$ In this notebook, she organized the literature into the following five categories: 1) duets, 2) duet collections, 3) two-piano pieces, 4) two-piano collections, and 5) pieces for three or more at one or two pianos. She also cross-referenced pieces according to musical style period (Baroque,

\footnotetext{
${ }^{6}$ James Friskin and Irwin Freundlich, Music for the Piano: A Handbook of Concert and Teaching Material from 1580 to 1952 (New York: Dover Publication Inc., 1973).

${ }^{7}$ Ibid., ix.

${ }^{8}$ Ibid., 321.

${ }^{9}$ Carolyn Maxwell, Maxwell Music Evaluation Notebook- Ensemble Piano Literature (U. S. A: Colorado, 1983).
} 
Classical, Romantic, Impressionistic, Contemporary), contemporary devices, dynamic range, easy-sounds-hard ${ }^{10}$, handicapped—one hand only, improvisation, jazz or popular idiom, memorization aids, rote [learning], modes and others scales, note-reading, sightreading, recital, group recital, rhythm aids, special appeal (for adults, boys, girls, spark up a stalled student, and teens), special music (for Christmas, dance, miscellaneous dances, folk music, Halloween, marches, and religious), and sure-to-please. ${ }^{11}$ This study "provides descriptive reviews of the complete spectrum of recommended piano music and materials. ${ }^{12}$ According to the author, this study also includes reviews of recently published or reprinted music, and descriptions of familiar and unfamiliar works.

In 1976, Frederic Ming Chang and Albert Faurot wrote a useful manual entitled Team Piano Repertoire: A Manual of Music for Multiple Players at One or More Pianos. ${ }^{13}$ This study is devoted to repertoire for two people at one piano, two people at two pianos, three or four people at two pianos, three people at three pianos, four people at four pianos, and arrangements, transcriptions, and recordings. The two main parts of this book deal with repertoire for two people at one piano and two people at two pianos.

In the introduction, the author provided some historical background to explain the growing popularity of team piano performance and repertoire. The number of two-piano compositions has increased quite a lot in the last fifty years, which has encouraged the forming of many more piano team partnerships. Chang also provided a very short summary of the book, Duo-Pianism by Hans Moldenhauer. ${ }^{14}$ Other information

\footnotetext{
${ }^{10}$ This is the term used by Carolyn Maxwell.

${ }^{11}$ Ibid., i.

${ }^{12}$ Ibid.

${ }^{13}$ Frederic Ming Chang and Albert Faurot, Team Piano Repertoire: A Manual of Music for Multiple Players at One or More Pianos (New Jersey: Metuchen, The Scarecrow Press, Inc, 1976).

${ }^{14}$ Hans Moldenhauer, Duo-Pianism (Chicago: Chicago Musical College Press, 1950).
} 
provided in this book includes the composer's country of origin, performance duration, and repertoire pagination.

Descriptions of difficulty in this book are based on the following four levels: ${ }^{15}$

1. Moderately easy - the level of the Moszkowski's Spanish Dances, Op. 12

2. Moderately difficult - the level of Grieg's Norwegian Dances, Op. 35

3. Difficult - the level of the Brahms's Hungarian Dances

4. Virtuoso- the level of the Stravinsky's Concerto for two Solo Pianos

Howard Ferguson wrote a book focusing on keyboard duets composed between the sixteenth and twentieth centuries. ${ }^{16}$ This book is divided into three chapters. The first chapter traces the history of repertoire for one piano/four hands and for two pianos in the Pre-Classical, Classical, Romantic, and Modern periods. He discussed composers from the sixteenth or early seventeenth century (such as Thomas Tomkins, 1572-1640) to the twentieth century (such as Malcolm Arnold, b. 1921). Ferguson mentioned that the expansion of this repertoire was due to "first, the gradual increase in the compass of instruments; secondly, the growth of music publishing; and lastly, the rise of a wealthy professional and merchant class." ${ }^{17}$ According to the author, the majority of works that are discussed in this book were written for the modern pianoforte. ${ }^{18}$

In the second chapter, Ferguson discussed some of the special problems and techniques that arise in duet and duo playing. ${ }^{19}$ The problems and techniques that he identified for two-piano playing include how to position the pianos, how to start together, and how to control the combined dynamics and tonal balance. He claimed that the way to

\footnotetext{
${ }^{15}$ Chang and Faurot, Team Piano Repertoire, xi.

${ }^{16}$ Howard Ferguson, Keyboard Duets from the $16^{\text {th }}$ to the $20^{\text {th }}$ Century for One and Two Pianos: An Introduction (New York: Oxford University Press Inc., 1995).

${ }^{17}$ Ibid., 5.

${ }^{18}$ Ibid., vi.

${ }^{19}$ Ibid., vii.
} 
place the two instruments should be based on the size of the room, and that the lids should be raised to their fullest extent in order to project the sound towards the audience. ${ }^{20}$ Regarding how to start together, he suggested that if the two pianos are placed side by side,

one player rests his hands on the keys for a moment; he then gives a preliminary beat in the tempo of the piece by a tiny upward movement of the hand, or even the index-finger - it need be no more than an inch or so provided it is precise. His partner follows the movement out of the corner of his eye, and thus both players can begin simultaneously. ${ }^{21}$

If the two pianos are placed tail to tail, "when the audience has settled down, one player gives two light taps on the pedal in the tempo of the piece. His partner can hear these, thus enabling both players to start on what would have been the third tap."22 Dynamic balance and tonal balance are essential to two-piano performance. Ferguson suggested that to control the volume when one has a tutti passage, think of $f$ when it is $f f$ and of $m f$ when you see $f$. The players should use less pedal than in solo performance, "to ensure that the pedaling of one player does not contradict what the other is trying to do." ${ }^{23} \mathrm{He}$ also stressed that both players must listen to each other in order to maintain a balanced sonority.

\section{Sources that Consist Mainly of Analyses} and Performance Suggestions for Selected Pieces

A total of three studies have been reviewed under this category. Two studies were reviewed that focus mainly on theoretical analysis of selected twentieth-century advanced-level piano duos. However, all three studies covered the development of the

\footnotetext{
${ }^{20}$ Ibid., 35.

${ }^{21}$ Ibid., 37.

${ }^{22}$ Ibid., 38.

${ }^{23}$ Ibid., 39.
} 
literature, as well as musical, technical, and compositional features. Other information discussed includes 1) value and benefits of two-piano study and performance (all sources except Ruth Neville), 2) performance challenges and goals (all sources except Eulalie Wilson Jeter), and 3) famous duo teams (all sources except Sister St. Cecilia Cutting). In 1978, Eulalie Wilson Jeter from Columbia University wrote a dissertation devoted to original two-piano music of contemporary American composers. The author mentioned that the purpose of this study is to develop and prepare a recital of two-piano music representing the compositional styles of twentieth-century American composers. ${ }^{24}$ However, the author only focused on the following five pieces, composed between 1940 and $1974,{ }^{25}$ for detailed analysis: ${ }^{26}$

1. Aaron Copland - Danzon Cubano

2. John Corigliano - Kaleidoscope

3. Norman Dello Joio - Aria and Toccata

4. Vincent Persichetti - Sonata, Op. 13

5. Alan Hovhaness - Vijao, Op. 37

Even though Jeter only focused on five pieces, she provided a useful overview of two-piano literature and performance. The author mentioned that the improvement of the instrument and the evolution of the tonal range affected the growth of the two-piano literature and performance in Europe over the past 175 years. ${ }^{27}$ But, the author claimed that the greatest popularity of two-piano playing today is in the United States, and that this has led to greater opportunities for two-piano performers. ${ }^{28}$

\footnotetext{
${ }^{24}$ Eulalie Wilson Jeter, "The Study, Analysis and Performance of Selected Original Two-piano Music of Contemporary American Composers" (Ed. D. diss., Teacher College, Columbia University, 1978), 2.

${ }^{25}$ Ibid., 141.

${ }^{26}$ Ibid., 2.

${ }^{27}$ Ibid., 8 .

${ }^{28}$ Ibid., 8 .
} 
The author also noted the value inherent in the study and performance of two-

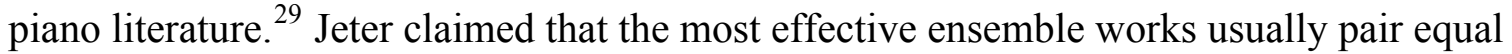
forces, with each part containing equal weight and content. ${ }^{30}$ Furthermore, sensitivity, expression, and interpretation are also required for two-piano playing. Both players need to listen for equality of attacks and releases, and also need to have good balance. ${ }^{31}$

Jeter claimed that the benefits of ensemble playing include the opportunity to perform as an accompanist, a leader or a soloist in a compositional work. In addition, she said that two-piano playing provides an opportunity for two performers to interact with each other and to learn from each other. Jeter also discussed some compositional characteristics featured in her selected compositions; these include chromaticism, repetition, imitation, free counterpoint, rhythmic qualities, formal patterns, and harmonic procedures (traditional, modal, polychordal, whole tone, cadential and non-cadential, and tonality through assertion). ${ }^{32}$

In 1992, Ruth Neville studied the preparation and performance of the following five twentieth-century compositions for two pianos, and then recorded each of them: ${ }^{33}$

1. Mel Powell: Setting for Two Pianos (1988)

2. $\quad$ Paul Davies: Titanic: From the Ocean Floor (1990)

3. Daniel Koppelman: Simple Harmonic Motion (1991)

4. Keith Johnson: Chiasmata (1989)

5. Claude Debussy: En Blanc et Noir (1915)

She analyzed both the performance problems challenging the duo-piano ensemble

\footnotetext{
${ }^{29}$ Ibid., 17.

${ }^{30}$ Ibid., 18.

${ }^{31}$ Ibid.

${ }^{32}$ Ibid., 139-140.

${ }^{33}$ Ruth A Neville, "The Study, Performance, and Recording of Selected Twentieth Century Repertoire for Multiple Keyboards” (Ph.D. Dissertation, University of California, San Diego, 1992), xii.
} 
as well as the musical and technical features of each composition. She also traced the origin of two-piano playing and transcriptions from one instrumental medium to another, and listed standard works in the two-piano repertoire. Regarding performance challenges, Neville noted that "the two piano ensemble is a reasonable representative of the orchestral idiom, approximating symphonic sonorities and proportions with its capacity for polyphonic textures, dynamic resources, and rhythmic designs." ${ }^{34}$ She highlighted this relationship by noting the number of composers who arranged orchestral works into two-piano works or vice versa. Most of the performance suggestions that the author provided could be very helpful to any ensemble team.

The author mentioned that the goals for solo piano playing (such as those related to balanced sonorities, melodic and polyphonic lines, and chordal harmonies) also apply to duo-piano playing. ${ }^{35}$ Duo-piano performance requires skillful handling of dynamics in order to avoid playing too loudly. The author recommended that both players should agree on and carefully plan their dynamics levels, ranging from the softest to the most powerful. ${ }^{36}$ She noted that the "physical size of body may also influence the production of sound. Matching the pianist with the appropriate choice of instrument can help to diminish outstanding discrepancies in an attempt to balance the pair." 37 Regarding pedaling, Neville observed that use of the damper pedals can enrich the sonority or create a messy sound. She claimed that "head or hand cues and/or counted beats will help to insure well synchronized pedaling." 38

\footnotetext{
${ }^{34}$ Ibid., 4.

${ }^{35}$ Ibid., 10.

${ }^{36}$ Ibid., 12 .

${ }^{37}$ Ibid., 14.

${ }^{38}$ Ibid., 16.
} 
Regarding tempo and rhythm issues, both players should agree and set a correct and comfortable tempo to avoid rushing. Using a metronome to practice will help to control the tendency to rush. Signaling is an essential issue for every type of ensemble. Eye contact, a 'nod' of the head, or other body movement will help to begin the piece or to coordinate simultaneous attacks and releases. Furthermore, sufficient practice and rehearsal will develop better communication between the two players. Neville also highlighted the importance of the 'line of sight' between duo partners; ${ }^{39}$ the setup of the pianos and the distance between pianists will directly affect signaling, eye contact, and physical cues (hand, wrist, arm, and body movement). ${ }^{40}$ Despite differences in their parts, both pianists should aim for consistency in their attacks and releases. The author also stressed that "in addition to a system of communication, the partners must listen attentively". ${ }^{41}$ She claimed that in order for a realistic evaluation, somebody coaching or taping the session, and/or listening to a good recording will help the performers. Finally, Neville maintained that even in ensemble teams, individual practice and preparation are each artist's responsibility. Performance practices and interpretation should also be discussed during the rehearsal sessions. She concluded that "the pianists share leadership in decision making in matters both aesthetic and mechanical."42

In addition to these two studies, another study was reviewed which focuses on performance aspects of two-piano music for high school students. In 1953, Sister St. Cecilia Cutting examined two-piano music training for high school students - more

\footnotetext{
${ }^{39}$ Ibid.

${ }^{40}$ Ibid.

${ }^{41}$ Ibid., 17.

${ }^{42}$ Ibid., 18.
} 
specifically, high school girls in a catholic secondary school. ${ }^{43}$ According to Cutting, the purpose of her study was to assist teachers and students by providing suggested techniques and materials for two-piano performance. Her entire study is presented in five chapters. The first chapter begins with the history of duo-pianism in America. The second chapter, which focuses on adolescents' learning of duo-piano ensemble, includes the following sections: 1) Duo-Pianism a Character Builder, 2) Emotional Adjustment and Duo-Pianism, and 3) Musical Values Derived from Duo-Pianism. ${ }^{44}$

Sister St. Cecilia Cutting discussed techniques for teaching two-piano compositions in the third chapter. This chapter includes information on the following:

1. Choosing partners and assigning parts

2. Stages in practicing

i. Preliminary work

ii. Individual practicing

iii. Ensemble practicing

3. Listening and watching

i. Listening

ii. Watching

iii. Signals

iv. Memory

v. Position of the pianos

4. Interpretative elements

i. Balance between parts

ii. Dynamics

iii. Pedaling

iv. Rhythm and tempo

v. Color

Finally, evaluations of twenty-five pieces from the two-piano literature were presented in chapter four. The author divided these twenty-five pieces into three levels of difficulty - intermediate compositions, moderately difficult compositions, and difficult

\footnotetext{
${ }^{43}$ Sister St. Cecilia Cutting, "Two-Piano Music for High School Students" (M.M. Thesis, Eastman School of Music of the University of Rochester, 1953), ii.

${ }^{44}$ Ibid., 16.
} 
compositions. She claimed that "it was decided that compositions of concert magnitude would not be included, since it has consistently been the purpose of the author to limit the discussion to the more modestly talented in preference to the few exceptional students." ${ }^{45}$

\section{$\underline{\text { Sources that are Primarily Historical Overviews }}$}

Three studies were reviewed which focus primarily on tracing the history of duo piano music. All of these studies provide lists of composers' names and specific titles of pieces.

Margaret McCarthy discussed two-piano music in an article entitled "Two-Piano Music Around Beethoven's Time: Its Significance for the College Teacher". ${ }^{46}$ The author claimed that ensemble performance is an effective way to increase students' musicianship. In addition, in terms of rhythm, it can also help them to develop strict synchronization and precise coordination. Furthermore, the author claimed that "it also helps shape their aural concepts in its demands for sensitivity to musical line, to clear texture, and to contrasts of dynamics, mood, and style." ${ }^{\prime 47}$ Therefore, she believed that the two-piano repertory that developed around Beethoven's time is a practical resource to meet many needs in the area of ensemble performance.

McCarthy claimed that many composers who lived around this time composed two-piano music; however, the most significant composer of two-piano music was Mozart. Another composer who was a major contributor to this repertoire is Dussek. Besides tracing the history of two-piano music, the author also provided a checklist of

\footnotetext{
${ }^{45}$ Ibid., 50.

${ }^{46}$ Margaret W. McCarthy, “Two-Piano Music Around Beethoven's Time: Its Significance for the College Teacher," College Music Symposium 17 no. 2 (Fall 1977): 131-143.

${ }^{47}$ Ibid., 131.
} 
this repertoire composed between 1770 and 1830. The list is arranged in alphabetical order by the composer's last name.

William Crandall Leech's 1941 thesis on two-piano music included discussions of original music for two pianos and for duet playing, as well as discussions of transcriptions, and additions of a second part as accompaniment. His thesis also included a list of works written for two pianos between the Renaissance and modern periods (arranged alphabetically by the composer's name), and a bibliography.

Leech noted some of the facts that brought two-piano performance into great popularity as an art-form in the music field today. First, the increasing size of orchestral groups gave rise to orchestral reductions for two pianos. In addition, the increasing availability of pianos, the socializing aspects of music (the desire to perform with others), and the increasing popularity of musical ensembles (e.g., choruses, orchestras, a cappella choirs) in the public school all increased the popularity of two-piano performance. ${ }^{48}$ In the second chapter, "Original Music for Two Pianos", Leech discussed only repertoire that was originally composed for two pianos. He examined repertoire by composers from the Renaissance to the twentieth century. He began with the earliest piece for two keyboards by an English composer of madrigals, Giles Farnaby (1560-cirea 1600). ${ }^{49}$ Leech also discussed repertoire for two keyboards/pianos by J. S. Bach, W. F. Bach, C. P. E Bach, Mozart, Beethoven, Clementi, Chopin, Schumann, Liszt, Saint-Saens, Brahms, Arensky, Cui, Stravinsky, Rachmaninoff, Debussy, Ravel, Bax, and some American composers. In this chapter, Leech provided some general background

\footnotetext{
${ }^{48}$ William Crandall Leech, "Music for Two Pianos." (M. M. Thesis, University of Kansas, 1941), 1-2.

${ }^{49}$ Ibid., 3.
} 
information about the pieces and some overall theory analysis such as the number of movements, the style and the form.

In the next three chapters, Leech discussed "Duet Playing", "Transcriptions", and "Addition Of A Second Part As Accompaniment". In the "Duet Playing" chapter, Leech traced the history of duet players from members of the Bach family to contemporary teams such as Josef and Rosina Lhevinne, Ethel Bartlett and Rae Robertson, and others. Chapter 4 was devoted to arrangements and transcriptions for two pianos. The fifth chapter was devoted to accompanying parts composed for teaching purposes such as Czerny's Velocity Studies, Op. 229b, and Etudes by Cramer and Bertini.

In 2003, Walden Hughes wrote an article for Clavier magazine about keyboard duets and duos composed during the past four hundred years. ${ }^{50}$ He noted that beginning with the Giles Farnaby composition "For Two Virginals", composers have continued to write music for two keyboards. ${ }^{51}$ For example, during the Baroque period, J. S. Bach wrote for two claviers for his sons, and C. P. E. Bach wrote Four Little Duets for two keyboards. In the classical period, J. C. Bach wrote a Sonata in $G$ for two keyboards in galant style. Clementi and Mozart also contributed some important two-piano compositions to the literature. During the nineteenth century, composers such as Schumann, Brahms, Liszt, Busoni, Rachmaninoff, and Saint-Saëns composed some twopiano compositions that have become standards in the two-piano repertoire. These pieces usually demand an advanced piano technique to play. During the twentieth century, composers such as Milhaud continued to write two-piano music. His piece, "Scaramouche," is considered by the author to be the most commonly performed two-

\footnotetext{
${ }^{50}$ Walden Hughes, "Music for Multiple Pianos During the Past 400 years," Clavier 42 (May/June 2003): 21-25.

${ }^{51}$ Ibid., 23.
} 
piano work in the repertoire. Besides repertoire for piano duet and two pianos, some composers also composed pieces for three players at a single keyboard and four players at four keyboards.

Finally, Hughes considered ensemble playing to be more enjoyable and fun than practicing alone everyday. Regardless if the piece is an arrangement or transcription or original composition, the student working on this repertoire might show a renewed interest and passion to learn and perform.

\section{Sources that Study Ensemble Playing}

Additional studies were found that focus on aspects of ensemble playing. Most of these studies mainly drew comparisons between duo performance and solo, duet, chamber, and orchestral playing (except for the Lhévinne and Claude Duncan). Other discussions and suggestions on how to play and practice duo music as well as how to choose a duo partner were also included in some of the studies (except for Paul Venable Turrill and Duncan). In addition, most of the authors claimed that duo-piano music should sound like it is played by a single performer, cautioned performers not to overuse the pedal, and encouraged them to listen carefully to balance.

In her 1951 study, The Two-Piano Idiom: An Analysis and Evaluation, Turrill discussed the duo-piano repertoire from the Renaissance period to the twentieth century. She discussed duo repertoire not merely for piano, but also included music for harpsichord, clavichord, spinet, and virginal. ${ }^{52}$ She also discussed transcriptions and arrangements. In her study, Turrill also reviewed some articles related to duo-piano

\footnotetext{
${ }^{52}$ Pauline Venable Turrill, “The Two-Piano Idiom: An Analysis and Evaluation,” (M. A. thesis, University of California, 1951), 2.
} 
literature published in the Harvard Dictionary of Music, The International Cyclopedia of Music and Musicians, Proceedings of the Musical Association, and Etude.

She observed that the tonal, technical, and interpretative resources of two-piano music are broader than solo piano music or even duets at one piano. She said, "the twopiano idiom possesses certain advantages_-as well as disadvantages_-peculiar to itself. These may be more readily understood if the resources are considered from three different aspects - the tonal, technical, and interpretative." ${ }^{, 53}$ When discussing the first aspect, the tonal aspect, she noted that in comparison to performances on a single piano, performances on two pianos have the potential for longer durations of sound (e.g., in passages where the accompaniment consists of extended tremolos or Alberti bass passages), slightly greater intensity (including a greater number of dynamic levels), and greater harmonic coloring, especially with the use of two damper pedals. ${ }^{54}$

When discussing the second aspect of duo-piano performance, the technical aspect, Turrill stated her belief that two-piano music is primarily for players of equal ability. ${ }^{55}$ She mentioned that both performers need to have a good control of rhythm and tempo, and should be able to listen to each other's sound quality and articulation. Turrill also observed that some aspects of performance are easier on two pianos than on one piano (e.g., delineating overlapping phrases, or performing polyrhythms), and some aspects are more difficult (e.g., feeling the same rate of rubato as one's partner).

When discussing the third aspect of duo-piano performance, the interpretative aspect, Turrill discussed the musicianship and individuality of two players. Usually, one may prefer an identical performance style or similar musical backgrounds of pianists for

\footnotetext{
${ }^{53}$ Ibid., 11.

${ }^{54}$ Ibid., 11-24.

${ }^{55}$ Ibid., 25.
} 
duo playing because this can reduce conflicting viewpoints between the players.

However, with different musical backgrounds, players could learn much from each

other. $^{56}$ Turrill provided some examples of famous duo-piano teams who regard the twopiano idiom differently. Some think that the two pianos should be considered as one enlarged instrument; others view them as a miniature orchestra, a concerto grosso, or as a chamber ensemble. ${ }^{57}$ In two-piano playing, each of the players usually takes turns as the soloist and accompanist; "the temporary soloist should be granted freedom to lead in the interpretation, and the accompanist should subordinate his own musical ideas until he, in turn, is given the principal melodic part." ${ }^{, 58}$ No matter whether the performers are leaders, followers, or partners, they should react spontaneously and creatively to any type of interpretation based upon the content of the scores. ${ }^{59}$

The study ends with an analysis and description of selected two-piano works written by composers from the Renaissance to the twentieth century. For each piece, the author discussed some performance practices and technical difficulties, and provided a brief theoretical analysis. Turrill concluded her study with a list of duo pianists.

In 1986, Chikako Sloan wrote a thesis comparing duo-piano and solo-piano performance. ${ }^{60}$ The author claimed that duo-piano performance is as important as solopiano performance, noting that "each of them has unique difficulties, strengths, and future trends."61

\footnotetext{
${ }^{56}$ Ibid., 31.

${ }^{57}$ Ibid., 32.

${ }^{58}$ Ibid., 32.

${ }^{59}$ Ibid., 33.

${ }^{60}$ Chikako Sloan, "Comparison of Duo-piano Performance and Solo-piano Performance" (M. M. thesis, The Ball State University, 1986).

${ }^{61}$ Ibid., 3.
} 
Finding enough variety of repertoire to create an interesting recital program is the first difficulty faced by duo-piano performers. The author also mentioned that preparing for duo-piano concerts is more time consuming than solo-piano concerts because the team must practice both separately and together from the beginning. According to Sloan, reaching agreement with one's partner on questions of musical interpretation is a serious difficulty in duo-piano performance. ${ }^{62}$ However, two-piano performance also provides the joy of team-work. ${ }^{63}$

The popularity of two-piano performance is growing. Sloan identified a couple of possible reasons for this growth. First, pianists who cannot maintain a career as a soloist begin to look for a new direction; then, as the number of two-piano performers increases, more composers take greater interest in writing for this medium, and two-piano performance gets increased exposure. ${ }^{64}$

In 1945, Bridenthal wrote a thesis based on the two-piano music which was available at that time through American publishers. The music that she discussed in this study is of a level of difficulty appropriate to a college piano major. ${ }^{65}$ The author sketched out the history of two-piano ensembles. She also included a summary of twopiano music and important composers, and a brief sketch of duo-piano teams. ${ }^{66}$ In addition, the author included a discussion of arrangements and transcriptions.

In addition to these discussions, the information she provided about the art of ensemble playing is beneficial to all readers. In this chapter, the author discussed the

\footnotetext{
${ }^{62}$ Ibid., 6.

${ }^{63}$ Ibid., 15.

${ }^{64}$ Ibid., 17.

${ }^{65}$ Dorothy Bridenthal, "A Critical Evaluation of Two-piano Music Available in American Publication" (M.M. thesis, North Texas State Teachers College, 1945), 1.

${ }^{66}$ Ibid., 2.
} 
antiphonal aspect which she thought is one of the most important resources of two-piano playing. ${ }^{67}$ According to the author, two-piano playing is well suited to presenting antiphonal textures such as setting off themes in contrast to each other and echo effects. She also said that two-piano performers have more freedom than duet performers in terms of using pedal and in terms of performance space, and that two-piano performance draws on the expressive and interpretive ideas of two different people.

She claimed that the two players need not agree with each other on every point, but should at least think and feel in common about the piece. ${ }^{68}$ Since two-piano performance is considered an important ensemble medium, the author suggested that elementary students should be encouraged to begin with some short exercises and simple tunes for two pianos during the beginning stages of study.

In the final chapter, Bridenthal also provided a useful table of information for each piece. Each table is divided into three columns: composer, title, and publisher. The tables are listed according to the difficulty level of each piece (length, speed, technical difficulties, form, harmonic ideas, piano idiom, and precision of ensemble). ${ }^{69}$

In a 1941 article in Etude magazine, Pierre Luboshutz and Genia Nemenoff talked about the art of two-piano playing. They discussed the enjoyment of playing with a partner, as well as the benefits and goals of two-piano playing, the differences from solo playing, recommended practice techniques, and issues of pedaling. ${ }^{70}$

The authors claimed that in duo playing "the team-work must be of the highest order, requiring that delicate combination of personal sympathy and technical equality

\footnotetext{
${ }^{67}$ Ibid., 15.

${ }^{68}$ Ibid., 19.

${ }^{69}$ Ibid., 30.

${ }^{70}$ Pierre Luboshutz and Genia Nemenoff, “The Art of Piano Ensemble," Etude 59 no. 1 (January 1941): 5, 58.
} 
that permits the partners to work out and to carry out their interpretations with artistic satisfaction." ${ }^{, 71}$ To achieve this, they noted that the sooner the duo partners begin learning two-piano ensembles the better it is. They suggested that teachers always encourage their beginning students to play short exercises and simple tunes together.

Another article about two-piano playing was published in the December 1933 issue of Etude magazine. The authors, Josef Lhévinne and Rosina Lhévinne, claimed that two-piano performers need to express musical thoughts rather than just simply striking the keys. Like solo performers, two-piano ensemble performers also need to study the score carefully, balancing statements, setting themes in contrast, considering phrasing, and planning how to unify the whole piece. ${ }^{72}$

In the article, the Lhévinnes suggested that the best ensemble playing occurs only when the players are in sympathy with each other, and when they are able to think and feel in common. ${ }^{73}$ However, this does not mean that they have to agree on everything; rather, they must be able to follow each other's habits of musical thought. The authors continued to explain that music is so elusive that neither player should be too subjective, but rather should try, "perhaps, to project themselves through a faithful adherence to the composer's thought." 74 Finally, the authors believed that performing with four hands at two pianos is even more interesting and more enjoyable than performing with four hands at one piano. With four hands at two pianos the sound is much richer and both players have greater freedom to draw upon pianistic resources from the bass, treble, and pedal.

\footnotetext{
${ }^{71}$ Ibid.

72 Joseph Lhévinne and Rosina Lhévinne, “Four Hands that Play as Two...," Etude 51 (December 1933): 809.

73 Ibid.

74 Ibid.
} 
Clyde Duncan wrote an article based on his experiences teaching duo-piano ensembles. He outlined the most basic and most essential goals of duo-piano playing. According to him, the reason that some college students take two-piano ensemble class is because it is required in their music curriculum. Therefore, his students usually came from different backgrounds, had different personalities, and different musical training.

Since each player came from a different background and had a different musical personality, Duncan claimed that "the instinctive player must learn to analyze or at least to reach some studied decisions with her partner". However, the weaker student of the duo team should be encouraged to draw upon her partner's strengths. ${ }^{75}$

The author felt that students' first piano ensemble experience should be playing duets with four hands at one piano because it is easier to control and listen critically to one instrument. After students develop skill at performing duets on one piano, then it should be easier to transfer to two pianos, despite the fact that both players will then have their own pedal, which requires even more careful listening. The author concluded that no matter how different their musical personalities are, that two performers still "can become one in a single musical experience."76

\section{Moldenhauer's Duo-Pianism}

Hans Moldenhauer's informative book, Duo-Pianism, was published in $1950 .^{77}$ This text is quite a complete handbook for two-piano performance. After tracing the historical development of two-piano performance, Moldenhauer discussed the nature,

\footnotetext{
${ }_{75}^{75}$ Clyde Duncan, "Teaching Duo-Pianism," Clavier 6 no. 2 (February 1967): 20-21.

${ }^{76}$ Ibid., 21.

${ }^{77}$ Hans Moldenhauer, Duo-Pianism (Chicago: Chicago Musical College Press, 1950).
} 
applications, and problems of two-piano playing. His book also includes a list of original two-piano compositions, brief analyses of theory and performance practice, a list of recorded two-piano music, and an annotated bibliography.

In the discussion of the nature, applications, and problems of duo-pianism, Moldenhauer investigated topics relating to artistic, creative, and educational issues. ${ }^{78}$ In terms of artistic issues, he claimed that performers and audiences are inspired and attracted by the orchestral richness of tone blending and by the precision of the concerted team work. In terms of composition, he noted that works for two pianos can contain new sonorities, with enlarged polyphonic and antiphonal possibilities. In his discussion of educational issues, he stated that "the team spirit in the pupil arouses his sense of responsibility and consideration, and indeed excites his greater alertness and resultant coordination." ${ }^{79}$

Moldenhauer discussed more details in relation to the artistic, creative and educational areas. He made suggestions concerning partnership (reasons and incentives, choice of a partner, individual qualifications, inferiority/superiority, and the problem of leadership), practicing (separate and joint practicing, proportion of emphasis on mechanics and aesthetics), mechanics and aesthetics (accuracy, signal systems, tempo and rhythm, phrasing, pedaling, dynamics, tone blending and balance, integration of elements, supervision of team work), program building (original works versus arrangements, some typical programs), and performance (memorizing, intuition during performance, stage presence, instruments and acoustics). ${ }^{80}$

\footnotetext{
${ }^{78}$ Ibid., 179.

${ }^{79}$ Ibid.

${ }^{80}$ Ibid., iii-iv.
} 
In addition to examining other aspects related to creative issues, Moldenhauer also covered topics related to the teaching of piano duos. ${ }^{81} \mathrm{He}$ discussed the use of the second piano as a pedagogic tool. According to Moldenhauer, a second piano has been used as a pedagogical tool during a piano lesson since Chopin's time. ${ }^{82}$ It is not only a good tool for teacher demonstration, but also, passages played simultaneously by teacher and student can develop rhythm accuracy and steady tempo. These can build up student confidence and develop better coordination and team spirit which are needed in ensemble playing. Moldenhauer also described how ensemble playing can increase the development of discipline and musical growth of the participant, ${ }^{83}$ and how it can increase student enjoyment. He stated that

experiments have shown that piano pupils of all ages as well as of various stages of accomplishment eagerly accept the challenge of duo-pianism whenever it is offered by the teacher. They respond with interest and display marked enjoyment. Their learning appears vitalized, and their progress furthered. There can be noticed the deep satisfactions of playing in the company of others. The team spirit being added to the individual initiative, no greater joy can be found in music." 84

In addition to student enjoyment, Moldenhauer also observed that audience reaction is often enthusiastic when there are duo pieces performed in a recital.

In terms of other benefits, Moldenhauer encouraged teachers to consider using two pianos to teach sight-reading. He also noted that, in order for both partners to achieve maximum educational benefit, their technical and musical ability levels should be matched as nearly as possible. ${ }^{85}$ Finally, Moldenhauer concluded that, for a "successful

\footnotetext{
${ }^{81}$ Ibid., 286-296.

${ }^{82}$ Ibid., 288-289.

${ }^{83}$ Ibid., 288.

${ }^{84}$ Ibid.

${ }^{85}$ Ibid., 295.
} 
adjustment to a social musical life", pianists should experience the equal partnership of duo-piano performance in an early stage of learning". ${ }^{86}$

This review of literature related to two-piano repertoire and performance reveals that authors have compiled lists/databases of the repertoire, have provided in-depth analyses of selected advanced-level repertoire, have traced the historical development of the repertoire and performance medium, and have offered advice related to ensemble performance (especially at the more advanced levels of study). However, almost no sources could be found that deal specifically with pedagogical aspects of teaching this repertoire to intermediate-level students, even though authors such as Bridenthal recommended that two-piano performance be begun in the early stages of piano study, and Luboshutz and Nemenoff felt that beginning pianists should begin two-piano performance early on by playing short exercises and simple tunes together, and Moldenhauer observed that pupils of all ages and levels of advancement enjoy and benefit from playing duos.

\footnotetext{
${ }^{86}$ Ibid., 296.
} 


\section{CHAPTER III}

\section{SUGGESTIONS FOR TEACHING TECHNICAL AND MUSICAL SKILLS THROUGH STUDY OF SELECTED PIANO DUOS}

Selecting and teaching appropriate repertoire for intermediate-level students is a

challenging but rewarding job because, in most cases, this is when students first begin to play music by recognized composers rather than playing the pedagogical exercises and pieces in their method books. While they usually enjoy this introduction to music from the standard repertoire, learning the first piece in any musical style is challenging until students feel comfortable with the specific techniques and musical characteristics associated with pieces of that style and period.

To reinforce the new techniques and style characteristics students are learning, teachers can also assign ensemble literature in addition to solo literature. Not only can this ensemble literature help students master new techniques and concepts, but it can also help increase their motivation and enjoyment. In fact, as was noted in Chapter II, several authors suggested that students should begin to play ensemble music as early as possible.

Pianists have a lot of options for ensemble playing since they can play piano duets, piano duos, or chamber music with other instruments. However, the easiest option for teachers to find will probably be piano duets because most composers of piano ensembles have written piano duets rather than piano duos. Also it is more convenient for teachers 
and students to teach and rehearse since only one instrument is required. However, playing piano duos has certain benefits for the students. First, the scores are written using both treble and bass clefs as encountered in their solo repertoire. Second, each student can sit in the center of the keyboard as they do when playing solo repertoire. Third, students who do not share a keyboard with a partner never encounter any hand-crossing problems. Finally, pedaling for oneself is far easier than having to pedal for both members of a piano duet team.

The review of literature in Chapter II revealed that most duo-piano repertoire is written for advanced-level performers. While intermediate-level duos do exist, they are not as well known as the advanced literature which is typically performed in concert and on recordings. This chapter will focus on identifying selected piano duos which are appropriate for intermediate-level students, and will highlight different intermediate-level musical, technical, and ensemble skills that can be taught through the study of duo playing. Pedagogical discussions will present guidelines and suggestions for teaching and rehearsing, and will address the following areas of learning:

1. Rhythm

2. Phrasing and articulation

3. Dynamics

4. Musical style

5. Balance (between pianos, and/or within each piano part)

6. Pedaling

7. Coordination of the ensemble (watching, signaling, breathing)

\section{$\underline{\text { Rhythm }}$}

\section{Syncopation}

While piano students at the intermediate level have already been introduced to commonly used rhythms and meters, more complicated musical passages involving 
syncopation, triple against duple rhythms, and meter changes have yet to be encountered. A determining factor in assuring the student's success in mastering such passages is his ability and willingness to count silently during performance, something many intermediate students are still reluctant to do! When playing solo music, some students may just try to feel the beats instead of counting carefully and accurately. Learning and playing duo music will strengthen and improve this ability since duo performers not only need to count their own part but also the composition as a whole. Furthermore, the farther one sits from one's partner, the more difficult it is to follow his rhythmic cues, and thus the more independent each performer must be in the area of rhythm. In his dissertation, Moldenhauer observed that "the proper projection of the rhythmic currents can be likened to giving music its blood stream.." 87

At the intermediate level, syncopated rhythm appears frequently in keyboard music from many different musical periods; it is often used in twentieth-century music. Syncopation poses quite a challenge for young students because they need to switch the accent from a strong beat to a weaker beat.

"Country Blues" from Four Piece Suite composed by Richard Rodney Bennett is an excellent piece to use with intermediate duo pianists to reinforce syncopated rhythm. ${ }^{88}$ This piece features syncopated rhythm in both piano parts and the tempo is rather slow. Therefore, there should be less difficulty in combining the rhythms in both hands within each player's part or between the parts for the two pianos. The rhythm in the opening

\footnotetext{
${ }^{87}$ Moldenhauer, Duo-Pianism, 207-8.

${ }^{88}$ Please see Appendix A for a complete list of titles, composers, and publication information for each piece discussed in this study.
} 
measure, with its rhythmic anticipation, is repeated (exactly or with slight variation) fairly predictably throughout the movement (see Example 1).

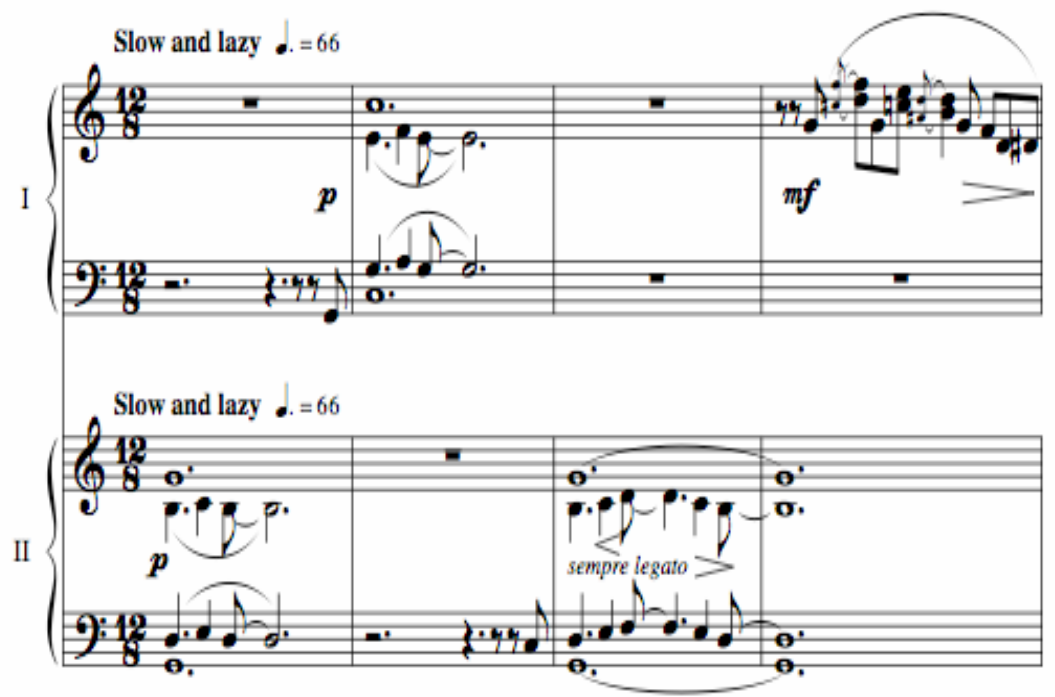

Example 1. Syncopated rhythm, "Country Blues" from Richard Rodney Bennett's Four Piece Suite, mm. 1-4

Within each piano part, both hands frequently perform the same rhythms, as they do in the opening three measures. Also, in the first twelve measures, the syncopated rhythm is played alternately by each player while the other performer holds a long tied note or observes rests (as illustrated in Example 1 above). Thus, in the opening measures of the movement, each performer gets to "try out" a syncopated rhythm by himself, with both hands playing the very same rhythm. Furthermore, the rhythms between piano parts later in the piece seem to align with each other at important places in the measure and thus reinforce each other. All of these characteristics make this a very good piece to use 
in teaching rhythm. Other benefits to teaching this piece are that it is in $12 / 8$ meter (which is usually not encountered frequently at the elementary level of instruction), and that young students usually enjoy playing jazz and blues.

During the elementary level of instruction, students often encounter imitation between parts in each hand in their solo repertoire. However, "Country Blues" would be an excellent piece to use in teaching students to imitate and/or respond not only to certain rhythms, but also to dynamic inflections and other expressive nuances heard in the other player's performance. For example, the blues style allows players to swing the rhythm a little bit; students should be encouraged to listen to their partner and respond with a similar amount of rhythmic "swing". A musical and unified performance of this piece requires students to pay close attention and listen carefully to each other.

Although rhythmic issues will probably be the primary pedagogical focus in teaching "Country Blues", other aspects which will likely require attention include a thick, chordal texture in the middle section of the piece, and a one-measure (m. 40) cadenza-like passage for the Piano I performer. However, since this piece is in a slow tempo, neither of these things should pose excessive difficulty for intermediate students.

Other piano duos that incorporate syncopated rhythm but pose additional challenges for intermediate duo pianists are Béla Bartok's two-piano arrangement of his "New Hungarian Folk Song" from Mikrokosmos (which will be discussed in detail under the Meter Changes category below), "Samba triste" (which is from the same suite as "Country Blues"), and "Cakewalk" from Carnival Suite composed by Alexandre Tansman. In "Samba triste", syncopated rhythms occur in both hands within one piano part as well as in both piano parts simultaneously. In "Cakewalk", not only is the tempo 
more rapid than in "Country Blues", but marked accents are indicated on the shorter note instead of the longer note of the syncopated rhythm, making this rhythm more unusual.

\section{Cross rhythms}

The first movement, "Marcietta" (Little March), in Alfredo Casella's Pupazetti 5 Musiche Per Marionette is an excellent piece to use with an intermediate-level duo team to help a student learn to perform eighth-note triplets against his partner's duple eighth notes (i.e., triple against duple rhythms) as illustrated in Example 2.

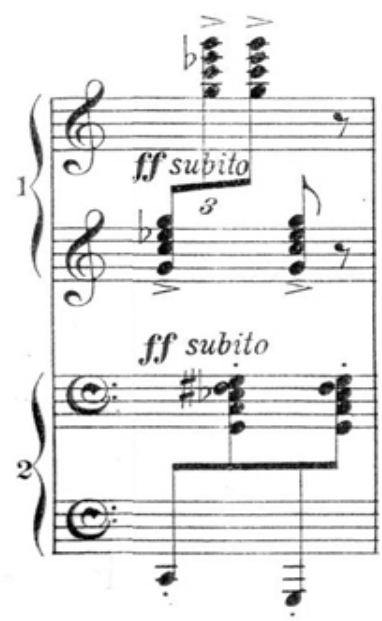

Example 2. Triple against duple rhythms, "Marcietta" from Alfredo Casella's Pupazzetti - 5 Musiche Per Marionette, m. 45

The challenge for the Piano II performer when playing this cross rhythm is to maintain a steady beat in a rapid tempo (around $d=192)^{89}$ without rushing. The challenge for the

\footnotetext{
${ }^{89}$ Although the composer indicated a tempo marking of $d=192$, this seems quite fast for a piece entitled "Little March". Therefore, the author would permit intermediate students to perform this movement at a somewhat slower tempo.
} 
Piano I performer is to perform even triplets, aligned properly against the second eighth note of the Piano II part.

When teaching students to decipher cross rhythms like 2 against 3 (which occur in measures 45-47 and 49-50), have them determine the lowest, common denominator of the two numbers and then figure out the exact placement of the rhythms relative to that number of beats. For example, the lowest, common denominator of 2 and 3 is 6 ; therefore, plot 6 numbers on a graph and insert the placement of the 3 notes in the triplet played by the Piano I performer on top and the 2 eighth notes played by the Piano II performer on the bottom as follows (see Example 3):

\section{Triplet played by Piano I: $\quad \delta \quad \delta \quad \delta$

6 beats: $1 \quad 2 \quad 3 \quad 3 \quad 4 \quad 56$ \\ Eighth-notes played by Piano II: $\delta \quad \delta$}

Example 3. Illustration of 3 against 2 rhythm, "Marcietta" from Alfredo Casella's Pupazzetti - 5 Musiche Per Marionette, mm. 49-50

A good way to start practicing and rehearsing this passage would be for the Piano II performer to begin by playing just the first and third eighth notes in $\mathrm{m}$. 45 (which are also the strong beats) while the Piano I performer plays the triplets. Then, the performers can try to put the two parts together, and if necessary both players can stop on the second beat of the measure in order to make sure they arrive here at the same time. When combining the parts, have both students play their parts together while counting to 6, playing each rhythm at the appropriate time as illustrated above. This should help them play this rhythm correctly. To reinforce this cross rhythm further, each student could try tapping 
the triplet in his right hand and the duple eighth notes in his left hand, thus playing both parts of the cross rhythm himself. Continued counting is necessary to mastering this cross rhythm.

Other challenges in this piece include distinguishing the many different articulations indicated in the score (e.g., staccato, portato, accents, and slurs); maintaining a rapid tempo without rushing; and creating a simple, childlike character (e.g., subito changes when indicated) appropriate for these puppet dances. Another area of difficulty might be the descending double thirds played in the right-hand part of the Piano I part (see Example 4).

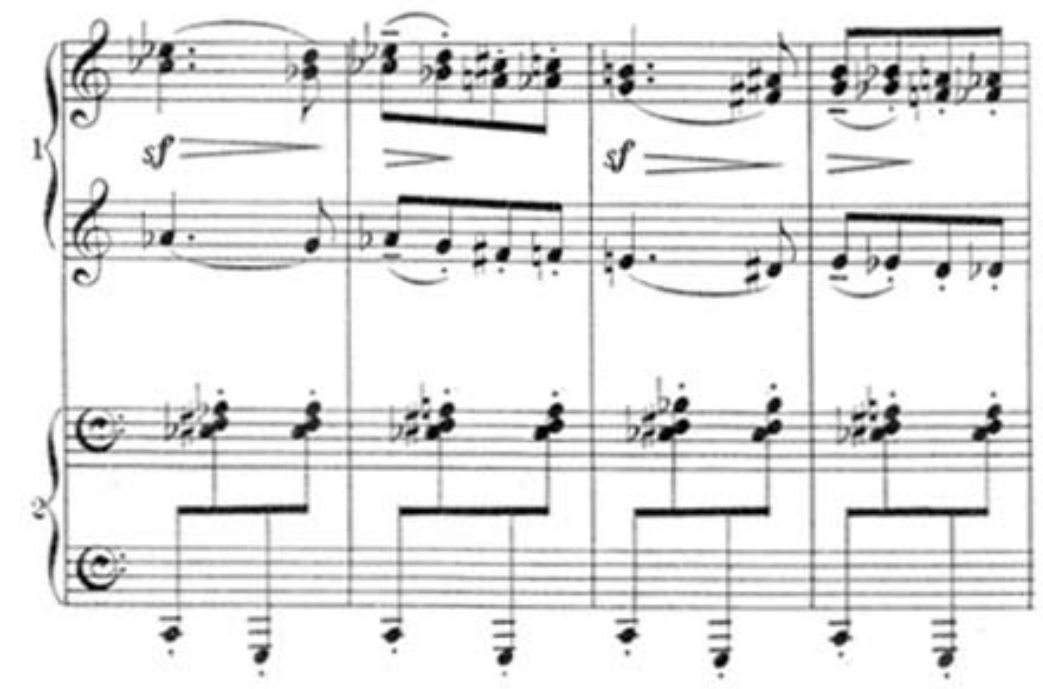

Example 4. Descending double thirds, "Marcietta" from Alfredo Casella's Pupazzetti - 5 Musiche Per Marionette mm.25-28

When practicing and performing such passages, the Piano I performer should always maintain the same fingerings while observing the different articulations. Another way to rehearse this passage would be for the student to take it apart and practice each pair of 
successive eighth notes using the correct fingering and articulation. Finally, the teacher should ask the students to describe how a marionette moves, and then to try to portray such movement in this piece. Since a marionette has jointed limbs controlled by strings, movements will not be graceful, but rather awkward and rigid in character. Therefore, the Piano II performer should always play his staccato eighth notes very accurately and evenly (as indicated by the "sempre rigidamente in tempo" indication in $\mathrm{mm}$. 22-23) in order to interpret a marionette's marching successfully.

Another good piece for intermediate-level students to use to hone their performance of cross rhythms is the fifth movement from Anton Arensky's Suite In Canon-Form Op. 65 entitled "Elegie - Canon At The Fifth". Rhythmically, this piece is more challenging than the previous piece discussed ("Marcietta"), since the triplet figures occur against different dotted rhythms rather than against steady eighth-note or quarternote beats in another hand or another piano. For example, in measure 2, triplets figures played in the left-hand part of Piano I are performed against different duple, dotted figures played in each hand of the Piano II part, as illustrated in Example 5 (mm. 1-2). Furthermore, ties increase the rhythmic challenges.

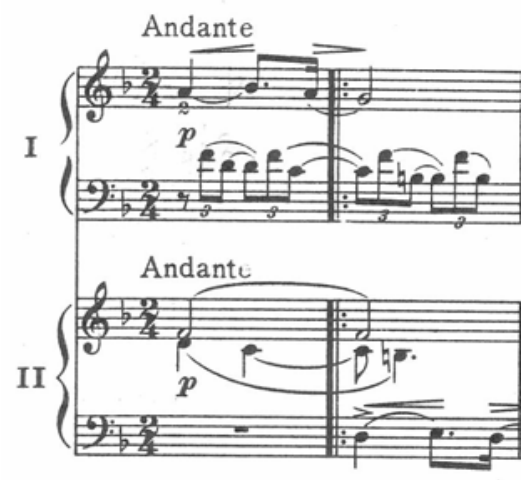

Example 5. Cross rhythm, "Elegie - Canon At The Fifth" from Anton Arensky's Suite In Canon-Form Op. 65, mm. 1-2 
If the Piano I performer's bass line and the Piano II performer's alto line on beat 1 of measure 2 were plotted on a graph comparing them to the lowest common denominator, they would line up just like the cross-rhythms in "Marcietta" except for the added ties and the fact that the dotted-quarter note will continue to sound throughout the entire measure (see Example 6)

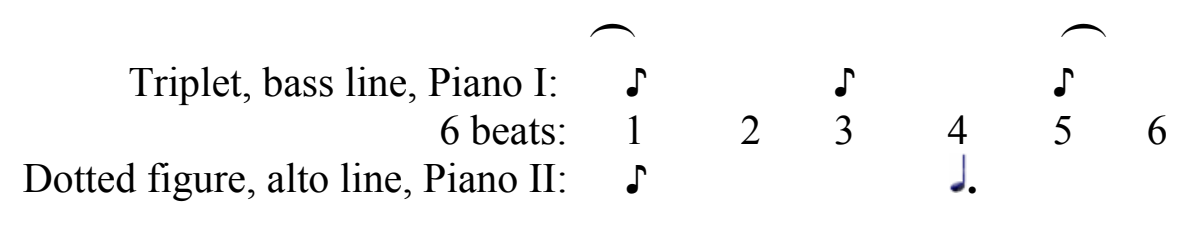

Example 6. Cross rhythm, "Elegie - Canon At The Fifth" from Anton Arensky's Suite In Canon-Form Op. 65, mm. 1-2

However, beat 2 of measure 1 provides a different cross rhythm within the Piano I part; on beat 2 of measure 2, this same cross rhythm then occurs between the bass lines of both parts. In these cases, the beat is divided into four (to create the sixteenth note) and into three (to create the triplet) generating a lowest common denominator of 12 . Plotting this rhythm on a graph similar to the above will clarify the rhythmic placement of each note in these measures (see Example 7):

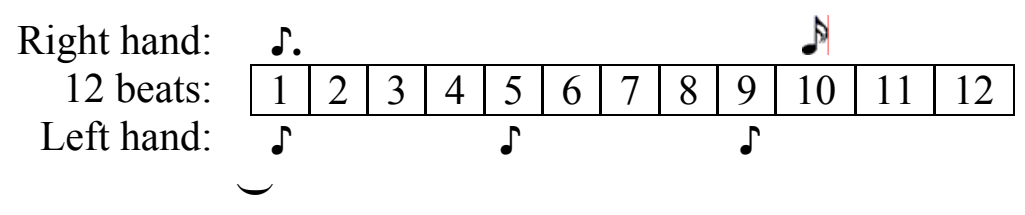

Example 7. A different cross rhythm, "Elegie - Canon At The Fifth" from Anton Arensky's Suite In Canon-Form Op. 65, mm. 1-2 
To practice and rehearse this rhythm effectively, the Piano I performer should begin by playing the cross rhythm in measure 1 while counting to 12 , playing each note at the appropriate time as illustrated above. Once this has been done correctly, the Piano I performer should repeat this cross rhythm while the Piano II performer claps the dotted figure. Then, the first two measures should be rehearsed with the Piano I part played as written and the Piano II performer playing only the bass line. Once the cross rhythm has been learned, the counting can be done silently and eventually omitted as the practice tempo is increased to a performance tempo. Also, the ties may be omitted until the cross rhythm can be performed comfortably, and can then be re-incorporated.

As the title indicates, this piece is a canon in which the left-hand melody in the Piano II part imitates the right-hand melody in the Piano I part a fifth ${ }^{90}$ lower, one measure later (as illustrated in Example 5). Again, students may have encountered a canon in a solo elementary-level piece, but have probably not yet performed one with another partner. Since this canon involves only the outer voices, it is easier for the performers to recognize and hear it. To be sure the students hear the canon, the teacher should begin study of the piece by having them sight read only the outer voices.

\section{Meter changes}

One of the challenges in learning twentieth-century music is meter changes. After finishing elementary method books (which unfortunately do not afford the student a lot of opportunities to play or explore twentieth-century sounds or techniques), meter changes can seem quite complicated to young intermediate-level students. Bartok's two-piano

\footnotetext{
${ }^{90}$ Although the composer identified this piece as a "canon at the fifth", the interval between the voices is actually a $12^{\text {th }}$.
} 
arrangement of his "New Hungarian Folk Song" from Mikrokosmos is a good piece to use when introducing meter changes to a young duo team. In this piece, the meter alternates between 4/4 and 2/4 (see Example 8).

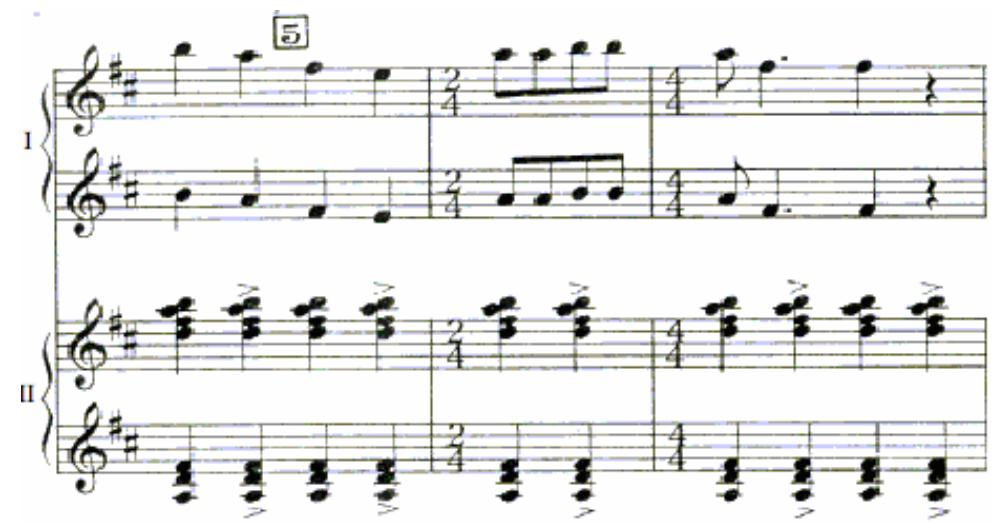

Example 8. Meter changes, "New Hungarian Folk Song” from Bartok's Mikrokosmos, mm. 5-7

As usual, both players should count as accurately and precisely as possible in duo performance. Since the quarter note remains the unit of pulse, students can just continue counting quarter notes. However, in playing this piece (with its meter changes, syncopated rhythms and marked accents on weak beats), intermediate-level players should also use a metronome in their rehearsal in order to keep the quarter-note beats precise. In this piece, counting out loud will be very helpful. To highlight and reinforce the accents on the weaker beats (i.e., the second and fourth beats) in the Piano II part chords, the performer should count the first and third beats more softly and the second and fourth beats in an accented manner. This should provide vocal support for correct performance. 
Another piece that includes quite a lot of meter changes is "Petit Poucet" from $\mathrm{Ma}$ Mere L'oye by Maurice Ravel. Although this piece features many different time signatures $(2 / 4,3 / 4,4 / 4$, and $5 / 4)$ which change frequently, the rhythmic patterns within these different meters are not complicated and the quarter note remains the unit of pulse (see Example 9).

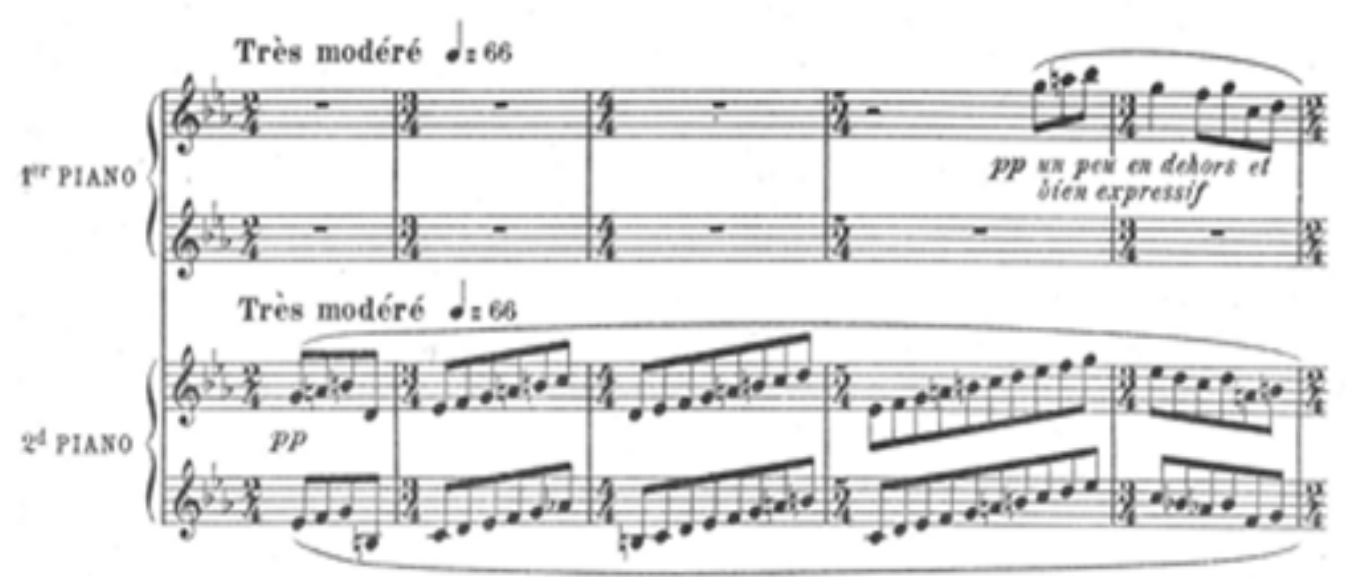

Example 9. Meter Changes, "Petit Poucet” from Ravel's Ma Mère L'oye, mm. 1-5

Unlike the meter changes in Bartok's "Hungarian Folk Song", the meter changes

in this piece serve a programmatic purpose. The Charles Perrault quote that Ravel included in the score explains what has happened to Tom Thumb:

Il croyait trouver aisément son chemin par le moyen de son pain qu'il avait semé partout où il avait passé; mais il fut bien surprise lorsqu'il n'en put retrouver une suele miette: les oiseaux étaient venus qui avaient tout mange. (He thought he could easily find his way by means of his bread crumbs that he had scattered wherever he had been; however, he was very surprised when he could not find even one crumb. The birds had come and eaten them all.) ${ }^{91}$

\footnotetext{
${ }^{91}$ Charles Perrault, "Petit Poucet”(Tom Thumb), Contes de Ma Mère L'oye: Histoires ou Contes du Temps Passé avec des Moralites (Stories or Tales of the Olden Times, with Morals); trans. Connie Arrau Sturm, quoted in Maurice Ravel, Ma Mere l' Oye (Paris: Durand \& Cie, 1910), 4.
} 
Illustrating the quote above, the meter changes in the opening measures (and elsewhere in the piece) portray the confusion of Tom's journey; the ascending parallel thirds (that suddenly drop down before starting to ascend again) and the additional beats in each successive measure create an unsettled and wandering feeling, portraying Tom's anxiety. He tries different paths going in different directions, but still cannot figure out the right way to get out of the forest and keeps coming back to the same place. The ascending scale accompaniment, with its mixture of pitches from the major and minor modes (e.g., m. 2), also conveys confusion. Tom's wandering can also be heard in the right-hand melody in measures $4,9,23$, and 27 . The three pick-up notes in the beginning of the phrase are in minor mode but have major inflections of the sixth and seventh degrees; these depict the uncertainty of Tom's way.

Playing with the metronome in the early stages of rehearsal will help to ensure that both players count precisely. In order to play all the eighth notes evenly, the teacher might want to suggest that the Piano II player use two hands to play all the double-third passages, for example mm. 13-17 and 42-50; the Piano I player may want to do the same thing in $\mathrm{m} .75$.

Other challenges in playing this piece are also related to understanding and interpreting the programmatic aspects of the music. For example, both players need to use the pedals carefully to create a sonority that supports and illustrates the story line. For example, students should use the una coda pedal to symbolize the small size of Tom, who is no bigger than his father's thumb. The use of half pedal is also suggested in this piece; the lack of a clear sonority can represent Tom's confusion and lack of a clear path 
home. The use of half pedal is probably a new experience for the intermediate-level duo team. The teacher should recommend half-pedaling by raising the side of the right foot off the pedal rather than holding the entire foot in the air. She should also demonstrate the difference in sound created by using a half pedal and using a full pedal. This will also help develop sensitive listening.

Other musical illustrations of the story line include the very high-pitched notes $\mathrm{G}^{\#} 7$ and $\mathrm{A} 7$ in mm. 51 and 53 (see Example 10) which represent the birds chirping and eating up all the bread crumbs.

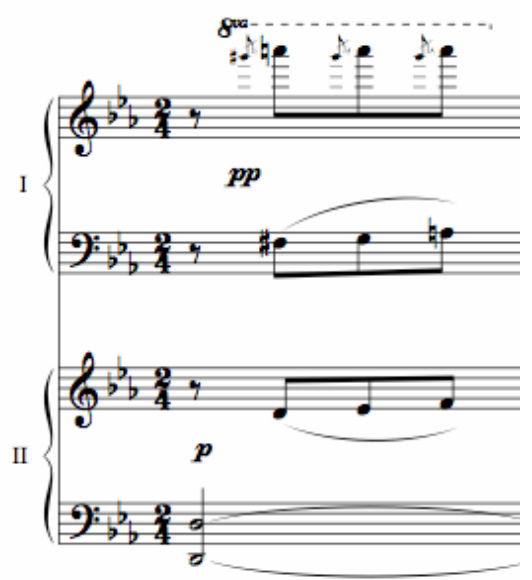

Example 10. Sounds of birds chirping, "Petit Poucet" from Ravel's Ma Mère L'oye, mm. 51

\section{$\underline{\text { Phrasing and Articulation }}$}

Usually, piano students first learn about phrasing and different kinds of articulation (e.g., legato, staccato, accent, slur, tenuto, portato) during the elementary level of study. At the intermediate level of study, the repertoire often requires more challenging combinations of various kinds of phrasing and articulation, and more sensitivity and nuance in this area of performance. Since the interpretation of phrasing 
and articulation can be more demanding in ensemble playing than in solo playing, performing piano duos is a wonderful way to hone these skills. In solo playing, the student can interpret the phrasing and articulation by himself without discussing or reaching agreement with another player, but in duo playing, pianists who perform the same material need to be matched in terms of attack and release to create a precise ensemble as well as a unified interpretation. For example, both players playing the same material should aim for the same duration of sound in staccato touch and should use the same kind of weight when playing slurs. This challenge will help develop sensitive listening and playing, as well as teamwork.

Only a small amount of music for two keyboards was written during the Baroque and Pre-Classical periods. However, Carl Philipp Emanuel Bach (1714-1788) composed a set of four pieces entitled Four Little Duets for Two Keyboards which is an excellent set to use when introducing intermediate students to duo playing. The second duet of this set offers great opportunities to develop their capability to play different articulations within one part (see Example 11).

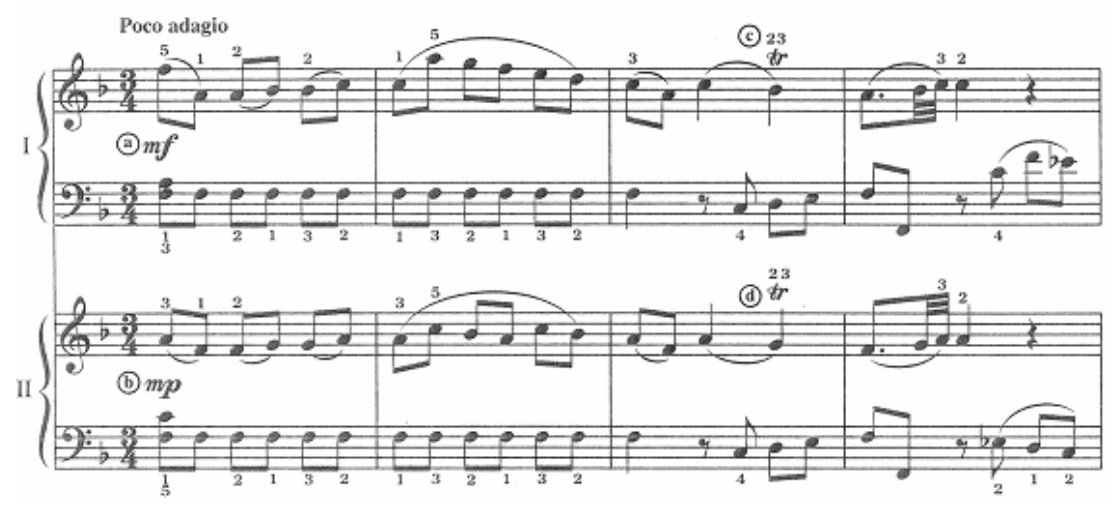

Example 11. Different articulations within one part, from C.P.E. Bach's Four Little Duets For Two Keyboards, no. 2, mm. 1-4 
It is also a great piece for teaching students to recognize phrasing. Since the composer did not indicate phrase markings, students must determine for themselves where phrases begin and end. Students need to realize that just because the composer did not indicate the phrases does not mean that none exist. To determine where phrases begin and end, students should identify cadences, sequenced material, dynamic changes and ornaments (assuming they are the composer's), etc. After delineating the phrases, students should notice that the phrase structure is symmetrical $(4+4)$ and cadences arrive at the same time in both piano parts. Furthermore, they can also try to select a slightly different dynamic level to help distinguish each phrase from the previous one. Throughout much of the piece, both right-hand parts have the same rhythm, with the Piano II performer playing a similar melody as the Piano I performer either a third or a sixth below; both bass parts are also very much the same in terms of pitch and rhythm. Sequences can be found in this piece as well (e.g., mm. 5-6). Due to its lack of complexity, students should be able to learn this piece relatively rapidly.

Another challenge in this piece is for both players to play the detached, left-hand repeated notes the same length without rushing. This requires counting carefully and listening to each other. Fortunately, the slow tempo, poco adagio, helps both players to avoid rushing on those repeated notes. At the same time they will have more time to listen to each other. In the early stage of rehearsing, they can try to count in sixteenth notes in order to help play the eighth notes the same duration. Furthermore, since both performers play mostly the same articulation in their right-hand parts, the weight and down-up motion when playing the slurs need to be considered in order to get the same 
attacks and releases. When both performers play trills simultaneously, the number of notes in these ornaments should also be the same.

Due to the proximity and similarity of lines, students should listen carefully to the balance, making an effort to project the soprano line in the Piano I part. In terms of voicing and balance, the next most important line to project is the bass line; since this occurs in both Piano I and Piano II parts (in the left hand), the part in the lowest register (usually the Piano II part) should be more prominent. Next, in terms of importance should be the treble line in the Piano II part, and finally the least important line to project will be the bass line in the Piano I part.

Another good piece to use when introducing phrasing and articulation to an intermediate-level duo team is the Waltz in $\mathrm{A}^{\mathrm{b}}$ Major, Op. 39 no. 15 by Johannes Brahms. The melody is played by Piano I performer throughout the piece while the Piano II performer plays arpeggiated chords as accompaniment (see Example 12 below). Even though phrase markings are not indicated in the score, the performers must still delineate and shape each phrase carefully. The phrase lengths can be clearly identified as $4+4+6$ (with repeats and variations of that material). Since the 6-bar phrase (mm. 10-15) consists of a sequence of three secondary dominants and their resolutions climaxing in mm. 14-15, students must be very careful in mm. 12-13 not to let the resolution from $A^{\mathrm{b} 9}$ to $\mathrm{D}^{\mathrm{b}}$ chords sound like a premature end to the entire phrase, mistakenly creating another 4-bar phrase. For the most part, harmony and cadences are quite clear in the piece, and students should be encouraged to identify as many of the chords (by letter name and/or by Roman numeral) as they can. 
In addition, to shaping the phrases dynamically, students also get an opportunity to interpret them rhythmically using rubato, which they should know is a performance practice which is widely used in Romantic music. Both pianists should discuss possible uses of rubato before they rehearse. In addition, singing phrases with their dynamic and rhythmic nuances will also help students shape them with a uniform interpretation.

Besides phrasing and rubato, students also need to pay attention to the different types of articulation. The two-note slurs, which Brahms marked in almost every measure of the melody in this piece, create a waltz-like feeling by highlighting the downbeats of each measure (see Example 12). The performer should not just depend on the pedal, but also needs to use finger legato when playing these slurs.

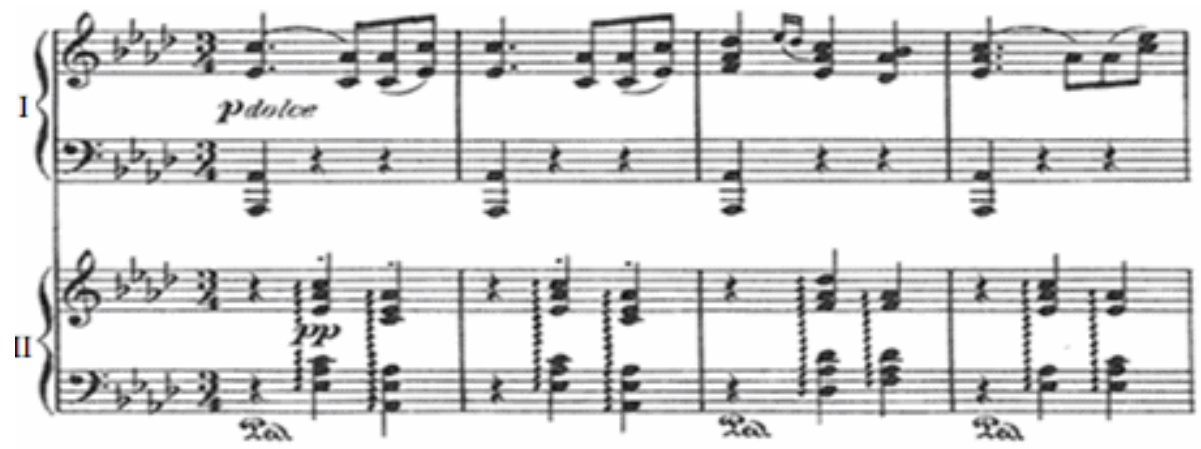

Example 12. Two-note slurs from Brahms's Waltz in $A^{\text {b }}$, Op. 39 no. 15, mm1-4

Using finger legato to connect chords with slurs while voicing the soprano line might cause some problems for intermediate students, especially those with small hands; however, wrist rotation, a relaxed tempo and rhythmic repetitions will all help the students. The Piano I player may also find it helpful to practice the chords with slurs on the piano lid first. The Piano II performer, who plays arpeggiated chords throughout the piece, should roll the chords like strumming a harp, with an even, gentle quality, and not 
too rapidly or slowly. Furthermore, these arpeggiated chords should played before the beat. Another challenge in this piece lies within the Piano I part. As shown in Example 12 , both hands play with different articulations; the right-hand part has slurs while the left-hand part has staccato chords. During the early stage of practice, the performer may want to play the left-hand part while singing the right-hand melody, and then try to imitate his/her own singing on the keyboard. One other slight problem in this piece involves the triplets in $\mathrm{mm} .30-35$ that the Piano I player may need to count carefully.

\section{$\underline{\text { Dynamics }}$}

Considering the potential for greater dynamic range, performances on two pianos can be much more dramatic and grand but also as beautiful as performances on one piano. Duo-piano repertoire can exploit more dynamic layers in order to create different tone colors and timbres. However, as in other areas of interpretation, duo pianists need to coordinate their treatment of dynamics with each other. For example, they need to communicate with each other regarding the pacing of a crescendo or diminuendo. In addition, achieving dynamic balance within and between parts is crucial to a musical performance. Duo playing affords a great opportunity for the teacher to encourage intermediate students to pay attention to dynamic balance.

The fifth piece from Cornelius Gurlitt's Eight Melodious Pieces, Op. 174 is a good piece to use to allow students to experience the drama and grandeur of the big sound which can be created by two pianos, and yet at the same time to pay attention to balance. This volume and character are indicated by the composer's Con moto energico, risoluto, $f$, and accent markings at the beginning of the piece (see Example 13). 


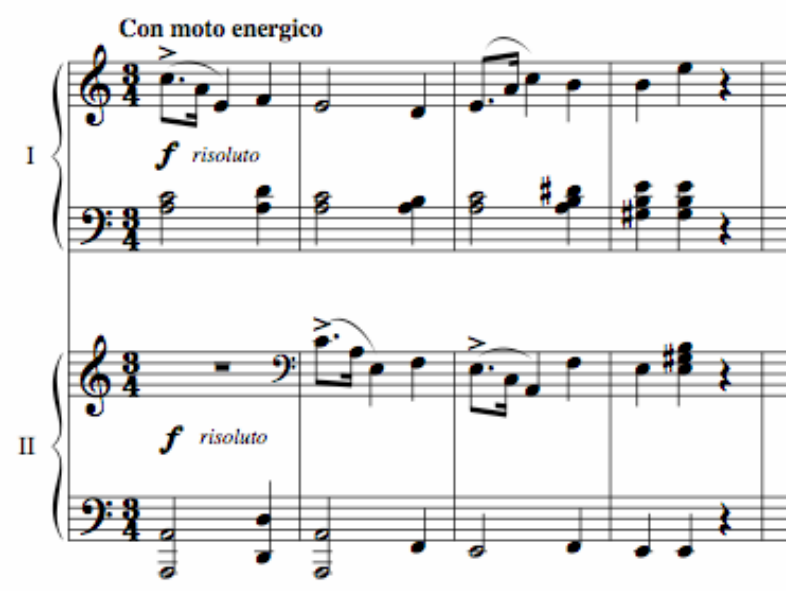

Example 13. Expression markings from Gurlitt's Eight Melodious Pieces, Op. 174 no. $5, \mathrm{~mm} .1-4$

This piece is divided into three sections, A (mm. 1-24) B (mm. 25-48) A (mm. 49-72), and dynamics are also important in this piece because they create contrast between the $\mathrm{A}$ and $\mathrm{B}$ sections as well as within the $\mathrm{B}$ section. The $\mathrm{A}$ section begins and remains $f$ or $f f$ throughout the section. However, the B section features three, eightmeasure phrases which range from $p$ to ff markings (see Example 14). Finally, the A section returns in measure 49 with risoluto and $f$ or $f f$ markings throughout. Careful observance of dynamic markings is crucial to the interpretation of this piece.

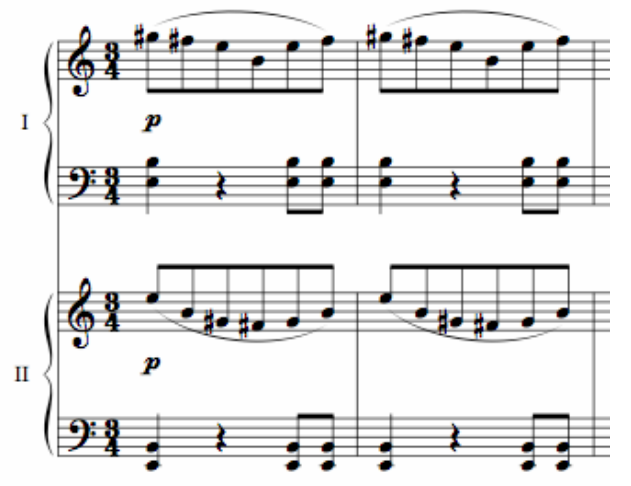

Example 14. Change in dynamic markings, from Gurlitt's Eight Melodious Pieces, Op. 174 no. 5, mm. 25-26 
For effective teaching of this piece to young pianists, the teacher may describe the themes in the A and B sections as representing different characters. This will encourage the students to use their imaginations and follow the dynamics markings faithfully. Since the exact same dynamic marking is indicated in both the Piano I and Piano II parts, the teacher should also suggest that the students listen more to the balance between melody and accompaniment. This can be challenging since the melodic material alternates between each performer; imitations and sequences can be found throughout the piece (see Example 13 above). To help students interpret this dialogue between parts, the teacher may want to suggest that they think of themselves as two people having a conversation. In addition, since phrase markings are not indicated in the score, the teacher may want the students to notice that the phrasing is symmetrical and the cadences in both parts occur in the same place, making it easier for them to shape their phrases and breathe together.

During the elementary level, students learn to play at $f, p, m f$, and $m p$ dynamic levels, and they also learn the meaning of the terms crescendo and diminuendo. However, young pianists usually still need to develop more control over their performance of dynamic nuances, both in terms of an evenly-paced crescendo and diminuendo and in terms of arriving at the desired dynamic level following a crescendo and diminuendo. The seventh piece in Arensky's Suite In Canon-Form, Op. 65 “Intermezzo: Canon at the Seventh", calls for students to imitate or respond to their partner's crescendo and diminuendo, which requires them not only to listen very carefully but also to control their performance of dynamics to match that of their partner. Since this is a canon, the melody is played alternately between the two piano parts at the interval of a seventh. Not only is 
the melodic material the same between the two parts, but the dynamic markings are usually the same as well. The challenge of playing this piece is to interpret the dynamic indications in a similar or complimentary way, which means that the Piano II performer must be very sensitive and listen very carefully to how the Piano I performer interpreted his dynamic indications (see Example 15).

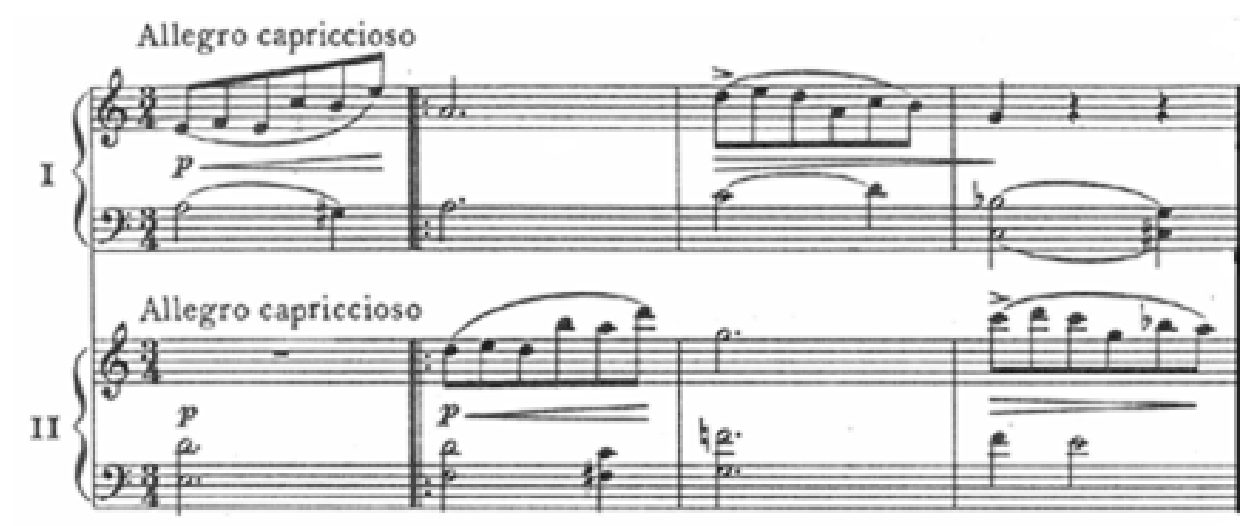

Example 15. Interpretation of dynamics, "Intermezzo: Canon at the Seventh" from Arensky's Suite In Canon-Form, Op. 65 no. 7, mm. 1-4

\section{$\underline{\text { Musical Style }}$}

Some people may not realize that the history of duo keyboard literature is almost as extensive as that of solo keyboard literature. Walden Hughes in his article "Music for Multiple Pianos During the Past 400 Years" stated that "while all students enjoy performing four-hand and two-piano literature, they seldom realize that piano ensemble repertoire has an extensive 400 -year history that began in the early 1600 s". ${ }^{92}$

Before beginning study of intermediate repertoire from different periods of music, students should develop some knowledge of music history so that they can observe

\footnotetext{
${ }^{92}$ Hughes, "Music for Multiple Pianos During the Past 400 Years," 21.
} 
appropriate performance practices and play their repertoire in a stylistic manner. This is necessary for playing piano duos as well as other piano literature. Not only do students need to know the historical background of the literature (which includes the social background, performance practices, etc), but they also should be familiar with the characteristics of keyboard instruments of the period. In order to perform a piece in a stylistic manner, it is important for young pianists to begin to recognize the different performance practices and style characteristics from various periods. The following intermediate-level duos can further develop and reinforce the student's understanding and appreciation of repertoire from the Renaissance period through the twentieth century.

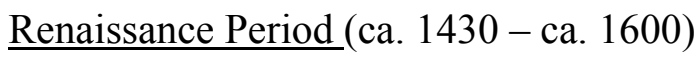

According to Han Moldenhauer, "to begin with the history of duo-pianism, it is necessary to retrace the development of the pianoforte as far as into the sixteenth century."93 The piano had not yet been invented at this time, and the keyboard instruments used during this period were the organ, clavichord, harpsichord, and virginal, the latter being the most popular keyboard instrument in England. Students need to know that the strings of the virginal and harpsichord are plucked rather then struck by hammers like the piano, and that this action and the sound produced affect the way we perform repertoire written for these instruments, especially with regard to articulation. Students should also know that the music composed during this time did not have any articulation, phrase, dynamic or tempo markings in the score. Thus, students need to be creative and to make informed decisions when interpreting these aspects of the music. A successful interpretation is based on knowledge of defining characteristics of Renaissance music.

\footnotetext{
${ }^{93}$ Moldenhauer, Duo-Pianism, 9.
} 
The Groves Music Online offers a thorough discussion of Renaissance music and cites the following traits (among others) which seem particularly characteristic of the keyboard music: ${ }^{94}$

- rhythmic fluidity and complexity

- fuller realization of the potentialities of the triad

- regulation of dissonance

- expansion of tonal range

- growing homogeneity of voices through contrapuntal imitation

- development of vocal and instrumental virtuosity

- increasing autonomy of instrumental music

Several of the characteristics discussed above are easily recognizable in a piece composed by Giles Farnaby (ca. 1563-ca. 1640) entitled "For Two-Virginals". This piece from Volume II of the Fitzwilliam Virginal Book, is one of the earliest known works for two keyboards. ${ }^{95}$ This piece is divided into two sections, and each section consists of four measures with a repeat sign. The phrase structure is symmetrical $(2+2)$ (see Example 16). Both Virginal parts are based on the same melody and accompaniment. The Virginal I part presents the original melody and accompaniment while the Virginal II part contains highly embellished versions of both melody and accompaniment. Thus, the Virginal II part is like a variation of the Virginal I part.

\footnotetext{
${ }^{94}$ Richard Marlow/Orhan Memed: "Farnaby, Giles", Grove Music Online ed. L. Macy (Accessed [January 23, 2007]), <http://www.grovemusic.com>.

${ }^{95}$ Maurice Hinson, Music for More than One Piano: An Annotated Guide (Bloomington \& Indianapolis: Indiana University Press, 2001), 62.
} 
For Two Virginals.

GILES FARABY
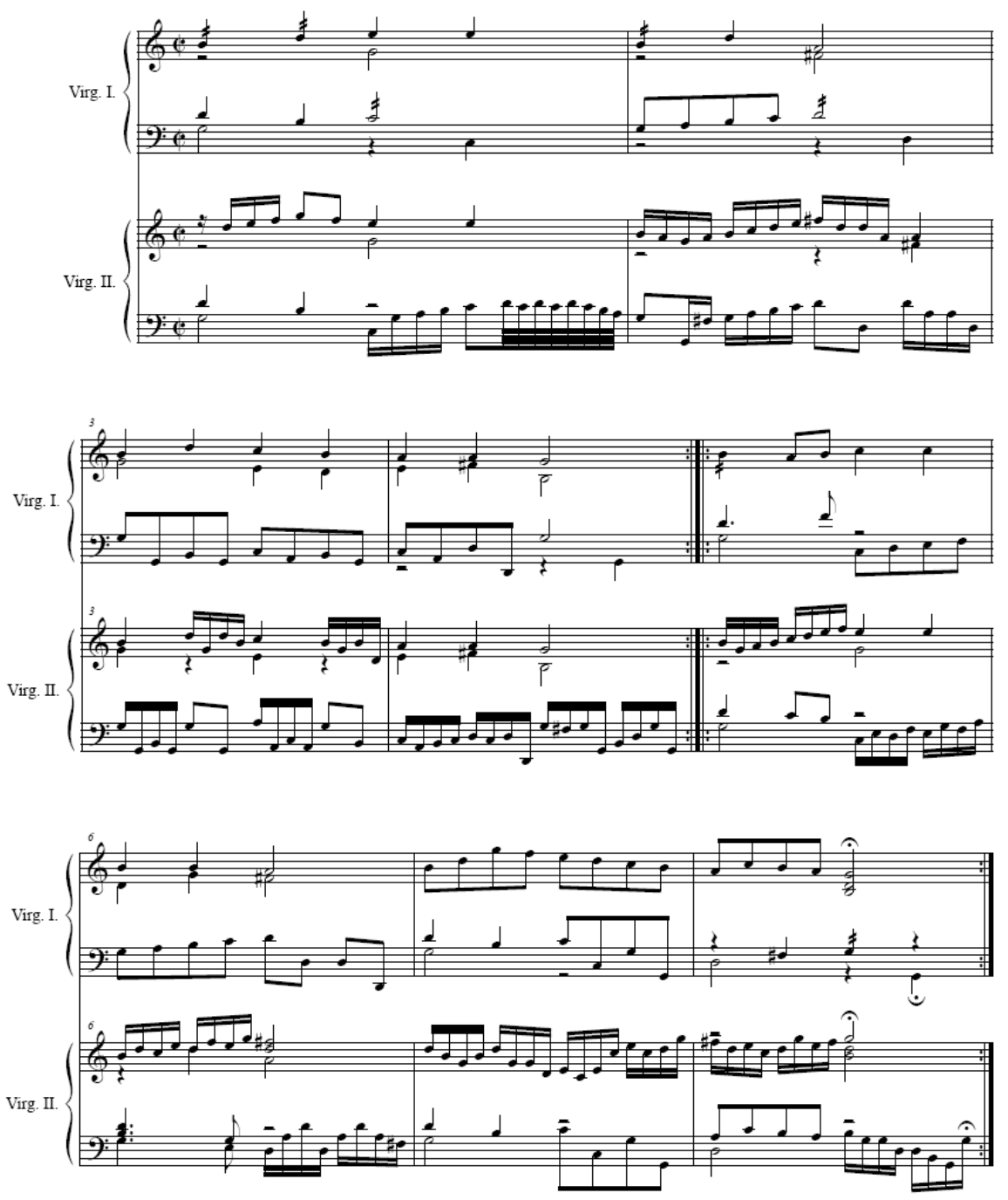

Example 16. "For Two-Virginals” from Giles Farnaby’s Fitzwilliam Virginal Book

This is a good piece to use when introducing Renaissance style to young pianists since it illustrates many of the characteristics of Renaissance style listed above. First of all, the rhythm of the Virginal II part is somewhat complicated (using rhythmic values as small as sixty-fourth notes). Secondly, despite the lack of any sharps or flats in the key signature, the frequent occurrence of $\mathrm{F}^{\#}$ in this piece and the $\mathrm{V}$-I cadences at ends of 
phrases clearly suggest a G Major tonality. Thirdly, this piece sounds more consonant than music of an earlier period. Fourthly, both voices are very homogeneous and very instrumental (rather than vocal) in nature.

The Virginal I part is not nearly as challenging as the Virginal II part in terms of technique. When performing this piece, both performers should use the most delicate touch; this requires finger independence instead of using arm weight, because this piece was originally composed for virginals. Teachers should also suggest using flexible wrists while playing the sixteenth notes. When learning this piece, students can also be creative by determining their own articulation, phrasing, tempo, and dynamic scheme. Regarding the articulation, students need to agree on which notes to perform non-legato and which ones to perform legato, and when to lift their hands. In addition, to achieve an improvisatory quality, students may want to take a little more rhythmic freedom in certain measures (e.g., m. 1, sixty-fourth notes; or m. 4 and/or 8, final group of sixteenth notes) where their partner plays a longer rhythmic value. However, most of the sixteenth notes should be even in the Virginal II part because they need to line up with the eighth notes in the Virginal I part. In terms of dynamics, students can also be creative in choosing different dynamic schemes for different phrases. Since the Virginal II performer has more notes to play, both players should pay attention to balance. In addition, the teacher may suggest that the Virginal II player highlight each melody note from the Virginal I part. 
Baroque Period (ca. 1600 - ca. 1750)

During the Baroque period, instrumental music became increasingly important, and more keyboard repertoire was composed during this time. Even though the piano had not yet been invented, composers still wrote music for other keyboard instruments such as the harpsichord, clavichord, and organ. Baroque keyboard compositions are staples in the performing and teaching literature and have remained part of the standard repertoire to this day. The most significant composers of keyboard music during this period are J. S. Bach, F. Couperin, Handel, and D. Scarlatti. However, very little music for two keyboards was composed during the Baroque period. Only a few works for two keyboards by J. S. Bach are notable. According to Maurice Hinson, there are only two sets of solo compositions and two concerti that J. S. Bach composed for two keyboards; these pieces are Two fugues from the Art of Fugue and Fourteen Canons, and two concertos for two keyboards and orchestra. ${ }^{96}$ Hinson considers all of these pieces to be advanced in level. Another composer who wrote keyboard duos is F. Couperin. Three duo pieces were found while doing this research, La Létiville, La Julliet, and Allemande á Deux Clavecins. The first two pieces were published together in the composer's collection, Troisième Livre de pieces de Clavecin. The last piece is from the Ninth Order, in Vol. II of Couperin's keyboard works published in $1716 .{ }^{97}$ All of these three pieces are highly ornamented.

In a discussion of Baroque repertoire, Roger Kamien cited the following traits (among others) which seem particularly characteristic of the keyboard music:

- unity of mood

- continuity of rhythmic patterns

\footnotetext{
${ }^{96}$ Ibid., 7.

${ }^{97}$ Ibid., 42.
} 
- continuity of melody

- melodies that sound elaborate and ornamental

- increased use of chromaticism

- use of terraced dynamics

- outer voices (soprano and bass) are more important

- polyphonic textures

- use of figured bass $^{98}$

Since both Renaissance and Baroque keyboard music were written for the harpsichord, they share many similarities in terms of performance practice and technical skills required. Proper performance of Baroque keyboard music requires hand and finger independence in order to play different articulations such as legato, staccato, portato, and non-legato. Finger independence is also necessary for evenness and clarity of ornamentation, a very important feature of Baroque music. Furthermore, performers of Baroque counterpoint need the hand and finger independence necessary to play two or more melodic lines or subjects simultaneously. Students also need musicianship skills and knowledge of performance practices in order to interpret aspects of the music (e.g., dynamics and phrasing) that were not notated by composers. When teaching Baroque repertoire to intermediate students, teachers should begin by providing some historical background for the Baroque period and discussing the mechanism and sound produced by a harpsichord. Learning more about the characteristics, society, and instruments of the period will help students to understand and play the music in a stylistic manner.

François Couperin's keyboard duos may be used to teach intermediate students many of the skills discussed above. A comparison of La Létiville and La Julliet reveals that both pieces are rather similar in terms of compositional style, and that both were written on three staves. Early editions of these pieces suggested that "these pieces in three parts may

\footnotetext{
${ }^{98}$ Roger Kamien, Music An Appreciation, 4th ed. (U.S.A.: McGraw-Hill, Inc., 1992), 129-131.
} 
be played on different instruments, but also on two harpsichords or spinets, i.e. the subject with the bass on one, and the same bass with the counter-melody on the other."99

Of these pieces, La Létiville is easier for intermediate students to play it as oppose to if features a lot of stepwise motion and scale passages (conjunct motion) rather than skips (disjunct motion). This piece should be performed as suggested above, with the Piano I performer playing the subject and the bass and the Piano II performer playing the counter-melody and the bass. The teacher should briefly explain that bass parts for keyboard instruments in the Baroque period were often doubled by a low melodic instrument such as double bass or cello, and that is why both performers can play this part.

As mentioned above, profuse ornamentation is one of the main characteristics of French Baroque music. In La Létiville, Couperin marked frequent trills and embellishments in both players' parts (see Example 17).

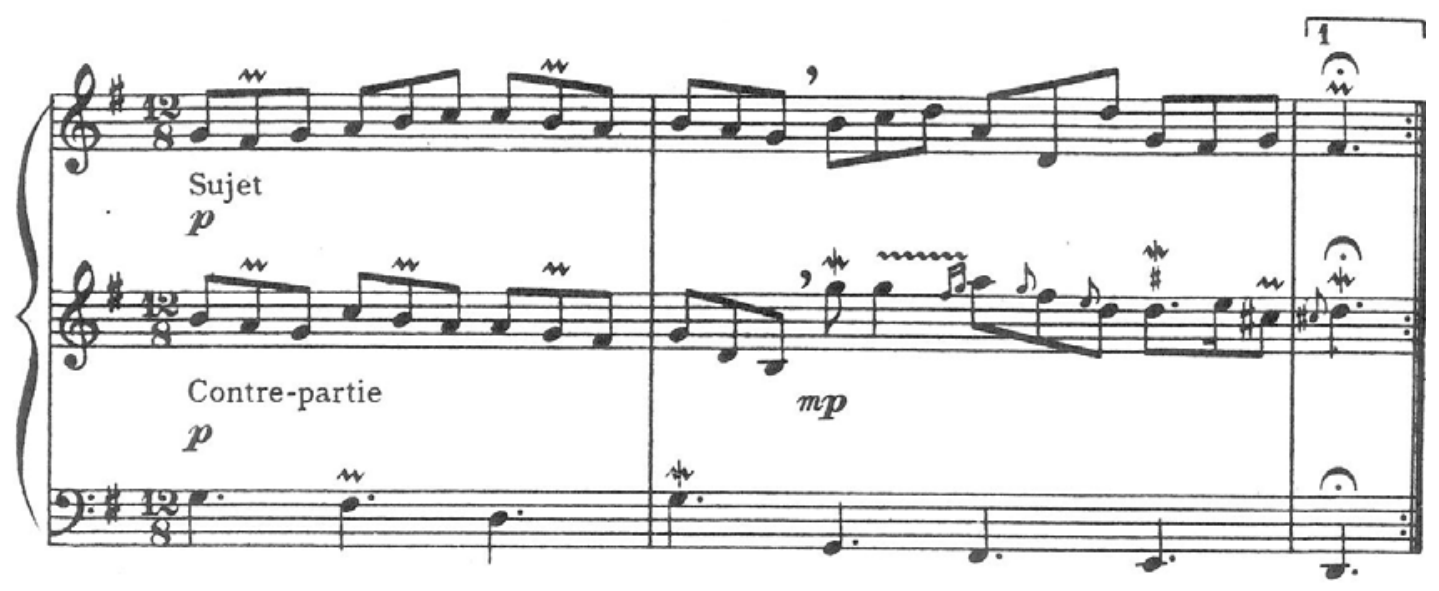

Example 17. Ornamentation, from F. Couperin’s "La Létiville” mm. 1-3.

\footnotetext{
${ }^{99}$ François Couperin, La Létiville and La Julliet (London: Oxford University Press, 1934), 2-3.
} 
The most challenging part of playing this piece is for both players to play each ornament precisely together. However, the large number of ornaments used by different composers from different countries can cause confusion for students, in terms of the length of the ornament, when to play it, and how to play it. Fortunately, F. Couperin wrote his own treatise, L'art De Toucher Le Clavecin (The Art Of Playing The Harpsichord) ${ }^{100}$, so students playing La Létiville should refer to this book. This treatise includes instructions on how to play Couperin's keyboard works as well as rules for playing each type of ornament that he used. The ornaments that are indicated in La Létiville are the trill, the short mordent, the appoggiatura, and the combination of lower appoggiatura and short mordent. The ornaments in the first three measures (see Example 17) seem to be representative of ornaments used in this piece. In L'art De Toucher Le Clavecin, Couperin specified the following rules for playing these ornaments: ${ }^{101}$

Trills should be performed as follows:

1. played on the beat

2. begun on the upper note

3. comprising a minimum of four notes and ending on the main note

Mordents should be performed as follows:

1. played with the main note accented

2. played on the beat and quickly followed by the lower auxiliary

3. begun and ended on the same main note

Appoggiaturas should be performed as follows:

1. played on the beat

2. accented and slurred softly to the main note, which resolves the dissonance

3. comprising half of the value of the main note

Combination of lower appoggiaturas and mordents should be performed as follows:

1. each follows the rules given above

\footnotetext{
${ }^{100}$ François Couperin, L'art De Toucher Le Clavecin, trans. and edit. Margery Halford (Alfred Publishing Co., Inc., 1974), 12-21.

${ }^{101}$ Ibid., 12-25.
} 
2. mordents are played after the appoggiatura has taken its time from the main note

Besides ornamentation, the articulation of each note is an essential issue to discuss. Since this piece was composed for harpsichord, it should sound light, clear, and delicate (as it would when performed on a harpsichord) rather than full and rich (as it could when performed on today's piano). Considering the mechanism and sound quality of the harpsichord, the teacher should advise students not to use the damper pedal, and to articulate each note individually. Other challenges for students include making decisions regarding dynamics and phrasing (because these are not marked in the score), and achieving an appropriate balance between parts. Since the Piano I performer plays the main theme at the beginning of the piece, the Piano II performer should pay careful attention not to cover this melody. Couperin also believed that the manner of fingering is important for good playing. He mentioned in this book, L'art De Toucher Le Clavecin, that "it is certain that a certain song played in a certain style of fingering will produce a different effect upon the ear of a person of taste."102

Classical Period (ca. 1750 - ca. 1820)

In the history of western music, the year of J. S. Bach's death (1750), is viewed as the ending of the Baroque period and the beginning of the Classical period. During the Classical period, which encompassed the "Age of Enlightenment", the style of living and society changed, so that more people could afford more luxuries and leisure activity such as going to a concert. Musicians began to compose for the public concert halls and opera theaters that were opening in many European cities and more public concerts were

${ }^{102}$ Ibid., 31. 
attracting a new audience. More people could also afford to pay for their children to take music lessons, and to purchase keyboard instrument(s) for home entertainment purposes. During the Classical period, the pianoforte was greatly improved, and it essentially replaced the older keyboard instruments, the harpsichord and clavichord. On the pianoforte, the performer could produce delicate shading of contrasting dynamics, projecting the melodic line while keeping the accompaniment soft at the same time. The damper pedal could also be used to project a richer, more resonant tone. Composers began to write keyboard music which took advantage of the pianoforte's new capabilities; it's richer, more resonant tone and timbre (compared to the older harpsichord and clavichord) allowed some composers to write keyboard music which had more of an orchestral sonority.

Musical tastes also changed toward a lighter style of music with more clearlydefined structures. The strict and intense counterpoint of the Baroque period was being replaced by the galant style, characterized by a light, sophisticated, and elegant quality. The music is characterized by a clear texture, periodic phrasing with frequent cadences, and emphasis on form and balance. The texture becomes homophonic with strong tonal centers. The technical and musical skills required for stylistic performance of Classical music included the following:

- distinction between two-note slurs, legato, and staccato

- balance of melody and accompaniment

- clarity in melodic figuration such as scale and arpeggios passages

- evenness when playing Alberti bass passages

- control of dynamic nuance

- consistency of tempo within a piece or a movement

- careful counting of rhythms (including rests) 
The most significant composers of keyboard music during this period include Haydn, Mozart, Beethoven, and Clementi. Among the piano ensemble works written by these composers, Mozart's duo music is most well-known. But, all of his piano duos are advanced in level. However, his contemporary, Clementi did compose two sonatas for two pianos, Op. 12 and Op. 46. Compared to Mozart's duos, Muzio Clementi's duos are more suitable for intermediate-level pianists. His Sonata in Bb major Op. 12, second movement Larghetto espressivo, can be used to teach many characteristics of slow movements from Classical sonatas to intermediate-level piano students.

Some typical challenges of performing Classical slow movements that can be practiced in this movement include expressive playing; achieving balance between melody and accompaniment (within one player's part as well as between two players' parts); and playing a short cadenza, different articulations, and variety of dynamic nuances (such as $f p$ ). In addition, counting shorter rhythm values and frequent changes between such rhythm values (e.g. from dotted eighth notes to thirty-second notes or from sixteenth notes to thirty-second notes), beginning phrases in the middle of a bar, playing long trills, and counting rests may also prove to be challenging for young pianists. Performance challenges related to balance, articulation, dynamic nuance, rhythm, and overall expression are already evident even in the opening phrase (see Example 18). 


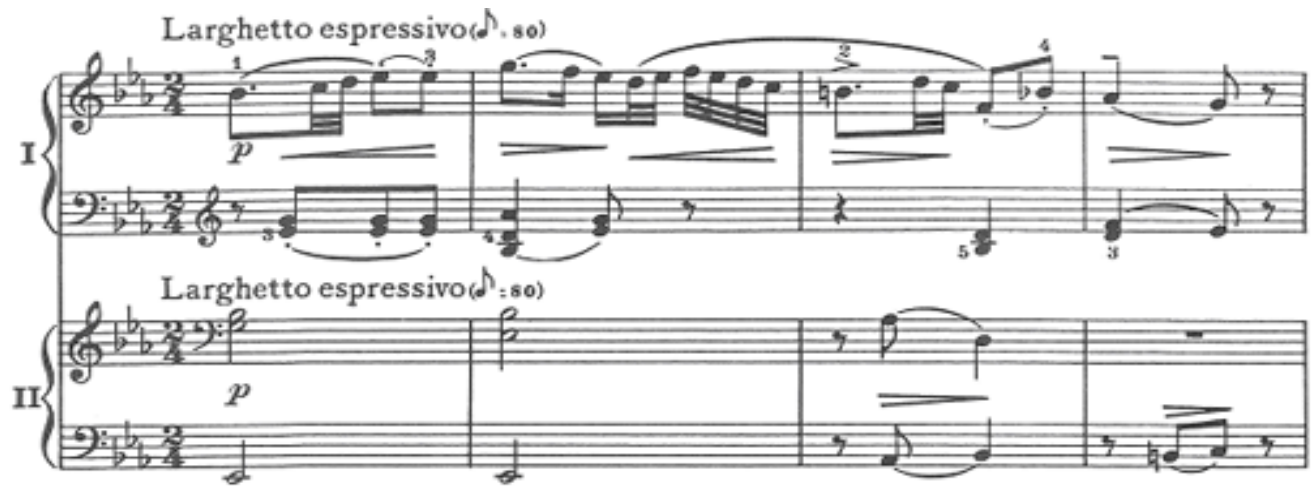

Example 18. Articulation, dynamic, and rhythmic challenges, Clementi's Sonata in $B^{b}$ Major Op. 12, II, mm. 1-4

The students should also notice that, even though the Piano II performer plays the accompaniment in this passage, this material should nevertheless be played expressively (as indicated by the composer's marking). This movement is also a good teaching piece for an intermediate piano duo team because of the relationship and interaction between both piano parts. Not only do both performers have a chance to play the main melodic material, but the imitation, echo effects and dialogue between the Piano I and Piano II parts require careful listening and control (see Examples 19-21).

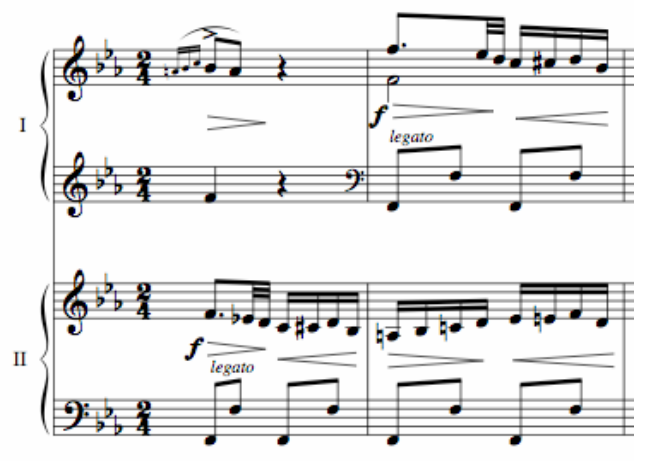

Example 19. Imitation from Clementi's Sonata in $B^{b}$ Major Op. 12, II, mm. 22-23 


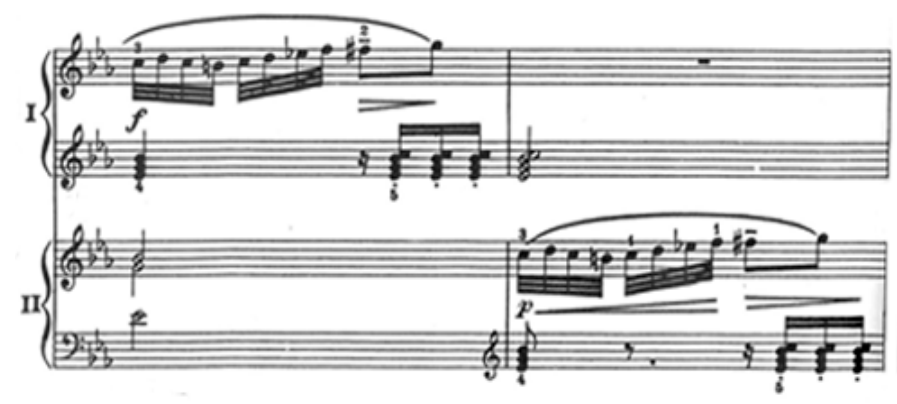

Example 20. Echo effect from Clementi's Sonata in $B^{b}$ Major Op. 12, II, mm. 1920

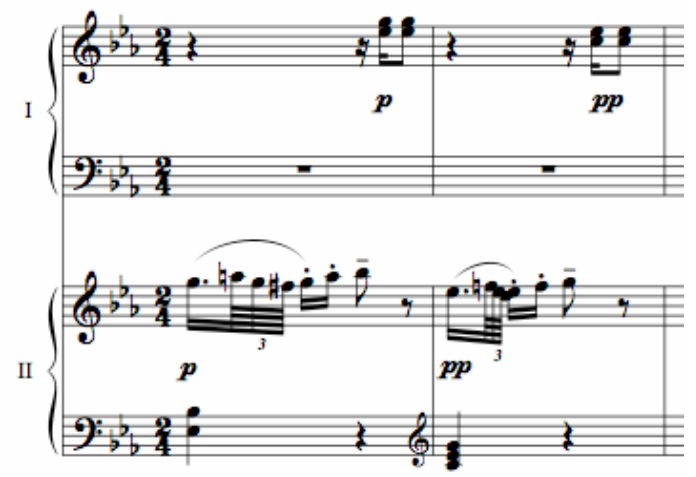

Example 21. Dialogue between parts from Clementi's Sonata in $B^{b}$ Major Op. 12 , II, mm. 26-27

To teach this movement effectively to an intermediate duo team, the teacher should point out that this piece is in A (mm. 1-16) B (mm. 17-46) A (mm. 47-62) form. Noticing that the repeated A section is exactly the same as the beginning A section will allow students see that the amount of music to learn is much shorter than what they expect; this will save them time during practice. As is typical in Classical repertoire, the phrases are symmetrical $(4+4)$, and the cadences are quite clear. Key changes (from $\mathrm{E}^{\mathrm{b}}$ 
major to $\mathrm{B}^{\mathrm{b}}$ major to $\mathrm{E}^{\mathrm{b}}$ major in the $\mathrm{A}, \mathrm{B}$, and $\mathrm{A}$ sections respectively) are also clear in this movement. To help assure rhythmic accuracy, the teacher may suggest that the team count in a smaller rhythmic value (e.g., sixteenth notes) and since the tempo is rather slow, the students should be able to do this. Another rhythmic challenge involves the short, one-measure cadenza passage in the right-hand part of the Piano I part before the return to the A section in measure 46. This cadenza provides a good opportunity for the student to develop rhythmic freedom in a quasi-improvisational style. While the Piano II player waits for his partner to finish the cadenza, he should listen and watch his partner carefully so that both players can come in together on the downbeat at measure 47.

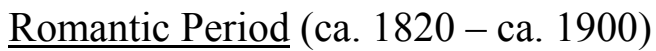

The early nineteenth century was a period of great change. The end of the French and American Revolutions helped people realize the importance of people's rights, emotions and individualism. Poets, artists, and musicians began to write, paint, or compose to express their inner feelings rather than to please or entertain others. Music composed during the Romantic period can be quite dramatic, passionate, personal and full of feelings.

The Industrial Revolution and the rise of the middle-class put music within reach of a larger audience. Middle-class people who entertained in their living rooms were now able to afford a piano(s) to entertain their guests. Keyboard music grew in popularity and more people wanted to learn how to play the piano. More parents began to hire musicians to teach their children how to play the piano at an early age. Composers no longer had to work for the aristocracy or for church patrons, but could earn their living by composing 
music for amateurs and by giving private lessons. Developments and improvements to the piano further increased its popularity. The range was enlarged and the damper pedals created greater resonance. Pianist-composers such as Liszt toured the world showing off technical skills and impressing audiences. Marcus Weeks noted that this led to "the birth of the piano recital as a star event." ${ }^{, 103}$ In addition, piano duos also became much more popular, leading to increased composition of repertoire for this medium.

Romantic composers such as Schumann, Chopin, Liszt, and Brahms all wrote piano duos. However, most duos written to "show off" technical skills are too difficult for intermediate-level students. Fortunately some shorter character pieces, such as some of the Brahms waltzes, are easy enough for intermediate-level students to play. Brahms arranged five out of his sixteen Waltzes Op. 39 for two pianos. One of these waltzes has already been discussed in the Phrasing and Articulation section of this paper, and another one will be discussed below.

In their book, Intermediate Piano Repertoire: A Guide For Teaching, Cathy Albergo and Reid Alexander provided an overview of characteristics of Romantic keyboard music which included the following:

- expression involving personal feelings

- variety of phrase lengths

- expanded expressive range through tempo rubato

- character and descriptive pieces

- complicated voicings

- wider dynamic markings

- emphasis on cantabile melody lines

- chromatic harmonies, thick textures and chord doublings

- expanded use of secondary dominants, diminished $7^{\text {ths }}$, and altered chords

- pedal used as a coloring device

${ }^{103}$ Marcus Weeks, Music: A Crash Course (New York: Watson-Guptill Publications, 1999), 81. 
- syncopation, more difficult rhythmic demands ${ }^{104}$

Albergo and Alexander also outlined the technical skills that an intermediate-level pianist will need to perform Romantic music:

- Expansion and contraction of the hand

- Complex inner voicings

- Octave stretch and octave fill-in

- Balance between hands, and within the hand

- Voicing of melodic lines

- Wide range of accompaniment figures

- Wider reading range due to expanded range of keyboard ${ }^{105}$

The Brahms Waltz Op. 39 no. 11 is appropriate to assign to a young intermediate duo team. However, it does present some rhythmic, melodic and harmonic challenges, including stylistic performance of expressive, cantabile melody lines using rubato and dynamic nuance (especially to color unexpected harmonic progressions). The wider keyboard range, wider range of dynamics, ornamentation, and double thirds can also challenge intermediate pianists.

This piece can be divided into two big sections, AA', that are separated by repeat signs. The A section begins in the key of B minor, but it ends in the key of the dominant minor, $F^{\#}$ minor. The $A^{\prime}$ section begins in the key of $F^{\#}$ minor and, after several measures (mm. 20-24) of unexpected harmonic changes, leads to tonic major, the key of B major in $\mathrm{mm} .25$. The phrase lengths are quite traditional $(4+4)$, the texture is traditional for a waltz (harmonized melody in the Piano I part and oom-pah accompaniment in the Piano II part), the tempo is not too fast, and the rhythm patterns are not too complicated. In fact,

\footnotetext{
${ }^{104}$ Cathy Albergo and Reid Alexander, Intermediate Piano Repertoire: A Guide For Teaching (Canada: The Frederick Harris Music Co., Limited, 2000), 8, 23.

${ }^{105}$ Ibid., 23.
} 
teachers should have students discover that the same rhythm pattern, the long-short-shortlong rhythm characteristic of Gypsy dances, unites the whole waltz (see Example 22).

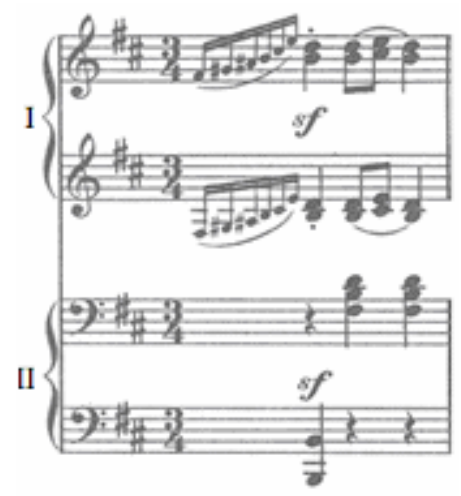

Example 22. Gypsy rhythm from Brahms's Waltz Op. 39 no. 11, mm. 1

In addition, teachers may also want to draw students' attention to the Hungarian dancelike rhythm at the end of the A section (mm. 15-16). Familiarity with this rhythm and the Hungarian style will be quite useful to students when they encounter them in advanced literature such as the Brahms Hungarian Dances or the Liszt Hungarian Rhapsodies.

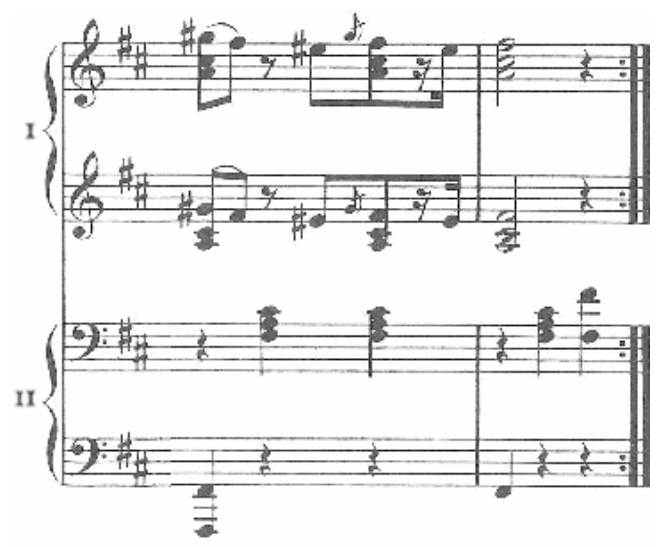

Example 23. Hungarian dance-like rhythm from Brahms's Waltz Op. 39 no. 11, mm. 15-16 
Although the notated rhythm is repetitive and uncomplicated, a stylistic performance of it using rubato may provide the greatest challenge in performing this piece. Teachers and students should decide together where to use rubato and should experiment with different uses to highlight phrase endings, dynamic changes, and/or harmonic changes. The performer who has the smallerst rhythm values should set the pace of the rubato; when both pianists have the same rhythm values, the performer who has the main melodic material should set the pace of the rubato.

While the greatest challenges in playing this piece involve musical style, a few technical issues must also be addressed. First, correct fingerings for the double thirds in the Piano I part help ensure a comfortable hand legato. Second, ornamentation should be played before the beat (in accordance with the performance practice during this time). Finally, the chromatic movement in the inner voices (the left-hand part of the Piano I part and the right-hand part of the Piano II part) in mm. 21-24 requires correct articulation and careful listening for proper melodic and harmonic shaping of the phrase (see Example 24). Teachers may want to have students play just these parts to assure a musical and unified interpretation. Proper balance of parts and projection of melodic lines over accompanying material is very important throughout this piece, but is not especially difficult. 


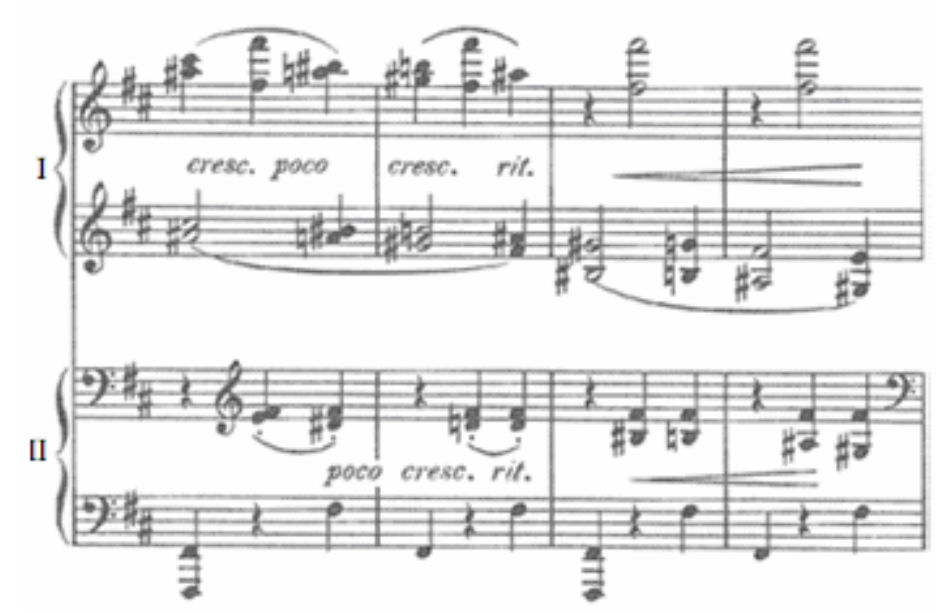

Example 24. Chromatic passage from Brahms’s Waltz Op. 39 no. 11, mm. 21-24

\section{$\underline{\text { Twentieth-century }}$}

In early twentieth centuries, artistic advances, scientific discoveries and two world wars changed people's lives and had an impact on their thoughts. During this period, people wanted to try new things and experimented with new approaches in music as well as in the arts. New inventions such as the radio, television, and phonograph became outstanding tools in the field of communication as well as in the field of music.

New technology not only inspired composers to find new ways to write music, but it also affected them politically, economically, and socially, which in turn affected their music. Several new styles of composition evolved including Impressionism, Neoclassicism, and Expressionism, and intermediate-level students should be introduced to them all.

The study of piano duos is a wonderful way to introduce intermediate pianists to the music of the twentieth century, since more composers wrote duo music than previous periods, and therefore, a greater number and larger variety of keyboard duos can be found. 
Some of the most important style characteristics of twentieth-century music have been summarized by Albergo and Alexander:

- Aleatoric ('chance') pieces

- Shifting meters, polyrhythms

- Use of dissonance

- Disjunct melodies

- Interval fingerings -4 ths, 5 ths, 7 ths, etc.

- Legato vs. staccato accents

- Harmonic extensions - 7ths, 9ths, 11 ths, etc.

- Atonality; polytonality; serialism composition

- Clusters, whole tone, pentatonic, triadic, quartal, quintal, modal harmonies

- New forms of notation

- Extensive use of pedal effects

- Layering of sounds

- Imagery

- More extensive and precise phrase, dynamic, and tempo markings ${ }^{106}$

Even though many of the twentieth-century duos found during this research were appropriate for advanced pianists, Otto Luening (1900-1996), an American composer, composed a piece entitled "The Bells of Bellagio" which is a wonderful piece for intermediate-level duo teams.

Luening composed this piece in 1967, having been inspired by the sound from the bells in the village church of Bellagio. ${ }^{107}$ This piece, which was written for two or three players at one, two, or three pianos, was composed on six staves. It consists of two movements, "Hail!" and "Farewell". The composer stated that "the piece should sound like bells; every note should be accented and the damper pedal should be held down throughout the entire piece." 108

Students can be introduced to the following twentieth-century musical characteristics through their study of this piece:

\footnotetext{
${ }^{106}$ Ibid., 36, 40.

${ }^{107}$ Ibid.

${ }^{108}$ Otto Luening, The Bells of Bellagio, (New York: C. F. Peters Corporation, 1973).
} 
1. use of real parallel thirds and sixths

2. free occurrence of dissonance

3. incorporation of both major and minor modes

4. cross relationships between parts (canon and augmentation)

5. exploitation of overtones that produce dissonance

Perhaps the most striking characteristics of this piece are its timbre, tonality, and canonic writing. While there are no V-I cadences and this piece lacks functional tonality, one nevertheless hears $G$ as the tonal center because of the beginning pitches $(G$ and $D)$ and because of the final $\mathrm{G}$ chord. Furthermore, almost every pitch used belongs to either the $\mathrm{G}$ major or $\mathrm{G}$ minor scale. Also, holding the damper pedal down throughout the piece combines the sounds of the pitches and their overtones to create a distinctive timbre; however, this pedaling and the resulting timbre and dissonance serve a programmatic purpose, reminding listeners of large, resonant bells whose sound lingers on, creating dissonance with subsequent pitches as the music continues.

Another notable compositional feature of this piece is its canonic writing. In each part of the first movement, the right and left hands play a melody one octave apart, and all three parts are in canon, beginning two beats apart. In addition, the Piano II part is an augmentation of the Piano I part, and the Piano III part is a double augmentation of the Piano I part (see Example 25). 


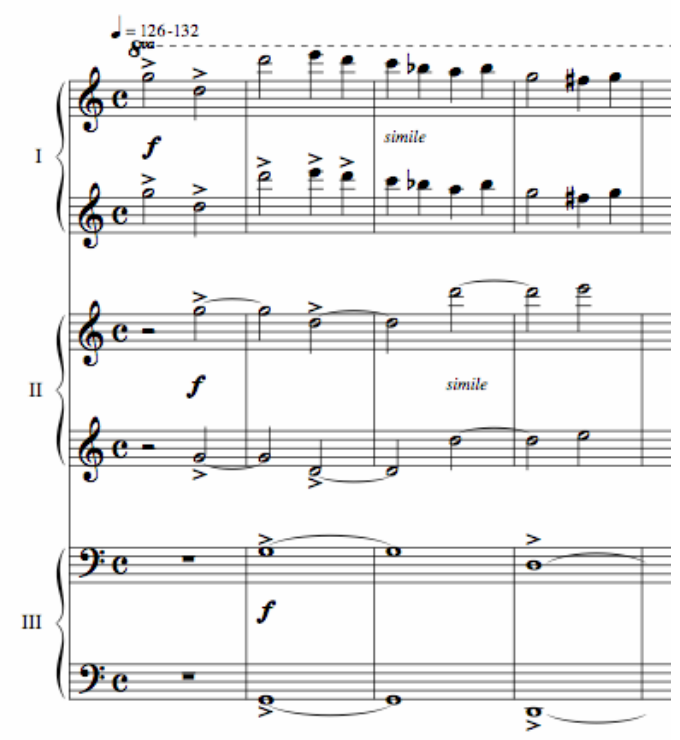

Example 25. Canon and augmentation, Luening's The Bells of Bellagio mm. 1-4

Furthermore, the second movement, "Farewell", is an inversion of the first movement, but it is now a double canon. The right-hand material in each of the three parts creates a canon, and the left-hand material in each of the three parts creates another canon. ${ }^{109}$ The rhythmic relationship between parts is exactly the same as in the first movement, featuring augmentation between each part.

The performance of this composition also has aleatoric aspects because the composer encouraged the players to find a variety of ways to perform it on a varying number of instruments. There are four obvious ways to perform this piece:

1. parts one and two

2. parts one and three

3. parts two and three

4. parts one, two, and three together

While the fourth way of performing this piece requires more than two pianos, the first three ways require only one or two pianos. The composer also encouraged performers to

${ }^{109}$ Ibid. 
find other ways to perform this piece. He noted that this piece is also "a particularly useful device in group piano teaching." 110

When assigning this piece to an intermediate-level duo team (two performers and two pianos), the first decision that needs to be made is which parts to include in the performance. While the teacher must consider the ability of the duo team, there are still a variety of performance options since the composer directed the performers to look for their own way to perform the piece. In the opinion of this author, an intermediate-level performer of the Piano II part should be able to handle portions of the Piano III part as well since these parts have longer rhythmic values than the Piano I part does. This performer could begin by playing octaves in each hand and then when thirds appear in both hands (starting in m. 28 in the Piano II part and m. 33 in the Piano III part), he could play either the right or left hand of the Piano II part in his right hand and either the right or left hand of the Piano III part in his left hand. Or, another suggestion would be for the second performer to play the Piano III part as well as choosing one line from the Piano II part.

To achieve a successful performance for young duo teams, the teacher should be certain that performers follow all the indications in the score faithfully. She should remind the students that if they only play parts two and three alone, Luening suggested that they take the tempo a little faster. ${ }^{111}$ Other performance suggestions might include emphasizing the longer note values (especially the notes with marked accents) so that these "bells sounds" and their overtones do not die away so quickly. Even though no phrase markings are indicated in the score, the performers should decide where to breathe

\footnotetext{
${ }^{110}$ Ibid.
}

${ }^{111}$ Ibid. 
together. In terms of dynamics, Luening only indicated an $f$ at the beginning of both movements. Teachers may want to guide the young performers by identifying the direction of each phrase and then suggesting that they can try to experiment with a variety of dynamic levels in order to achieve a different kind of sonority. Finally, since Luening indicated a fermata on the very last chord of this movement and since the pitches are all supposed to sound like bells, teacher might want to suggest that the students raise their pedals gradually after the fermata to let the sound gradually fade away (as would the sound of bells).

\section{$\underline{\text { Balance }}$}

The appropriate balance of parts within a composition is essential in every type of ensemble performance as well as in solo playing. All pianists should develop and train their ears to be sensitive to balance. Especially when two pianos are being played at the same time, one player can be easily overshadowed by the other if the balance is poor. The team should also consider that when the two pianos are placed tail by tail, the lid of one of the instruments should be removed, and they should adjust their balance accordingly. When two instruments with virtually the same tone color and timbre are played together, it is quite difficult for the performers to hear individual parts within the texture while they are playing. Therefore, to achieve a good ensemble, both players must begin by examining the score to discover what part(s) they play. Usually, the melody should be projected over the accompaniment, which should not overshadow the melody line. However, in many piano duos, both players have a melody part in one hand and an 
accompaniment part in the other hand. Furthermore, both players must be constantly aware of melody lines which shift back and forth between parts. That is why maintaining proper balance is one of the biggest challenges in duo playing. On the other hand, once the intermediate duo team learns to make careful adjustments to the balance of musical material both within and between each piano part, they will have developed more accurate and sensitive listening skills which will improve their playing of both duo piano and solo piano music.

"Valse Triste" by Reinhold Glière, the second piece in the set of Six Morceaux Op. 41 , is an excellent piece to use when teaching balance. After a four-bar introduction, the A theme (mm. 5-20) is presented in the Piano I part with long-short rhythmic patterns accompanied by a bass line and chords played in a waltz rhythm in the Piano II part (see Example 26).

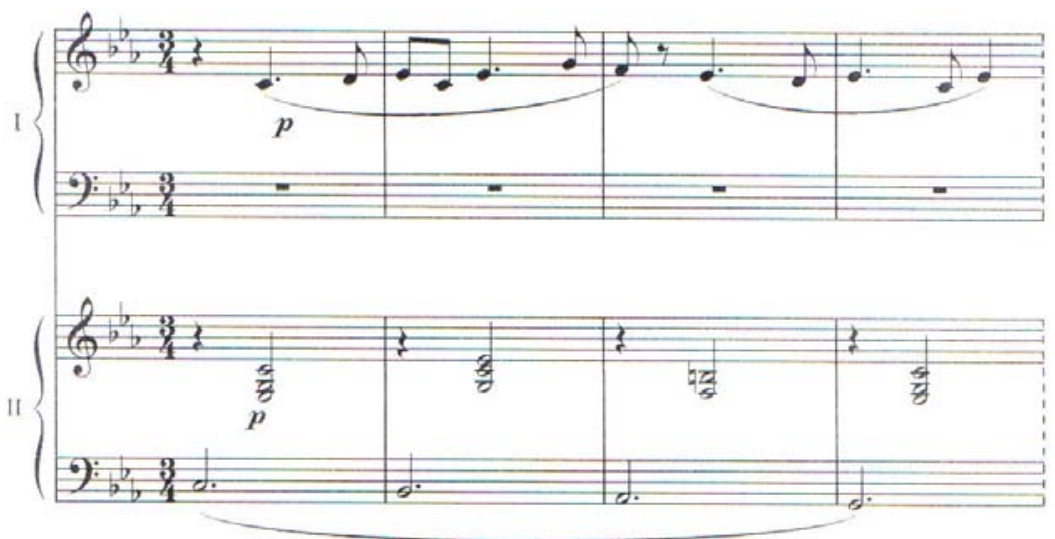

Example 26. Opening of the A theme, "Valse Triste" from Six Morceaux Op. 41 no. 2 by Glière, mm. 5-8 
In mm. 21-36, both performers play the A theme in their right hands (an octave apart), and the bass line and chords are divided between performers. In terms of balance, the projection of the melody is of primary importance, followed by the bass line and then by the chords. Doublings of parts are relatively less important. Therefore, when students perform this section of the piece (mm. 1-36), the melody played by the right hand of the Piano I performer is most important; also, the bass line played by the Piano II performer is relatively more important than the chords. When the melody line is doubled and played by both performers in $\mathrm{mm}$. 21-36, the Piano I right-hand part is still considered relatively most important; the doubling of the melody line an octave lower in an inner voice in the Piano II part is relatively least important.

The B theme, a scale-like melody line of eighth notes which begins off the beat, appears in $\mathrm{m} .37$ in the treble line of the Piano II part, imitated by the Piano I part two bars later (see Example 27).

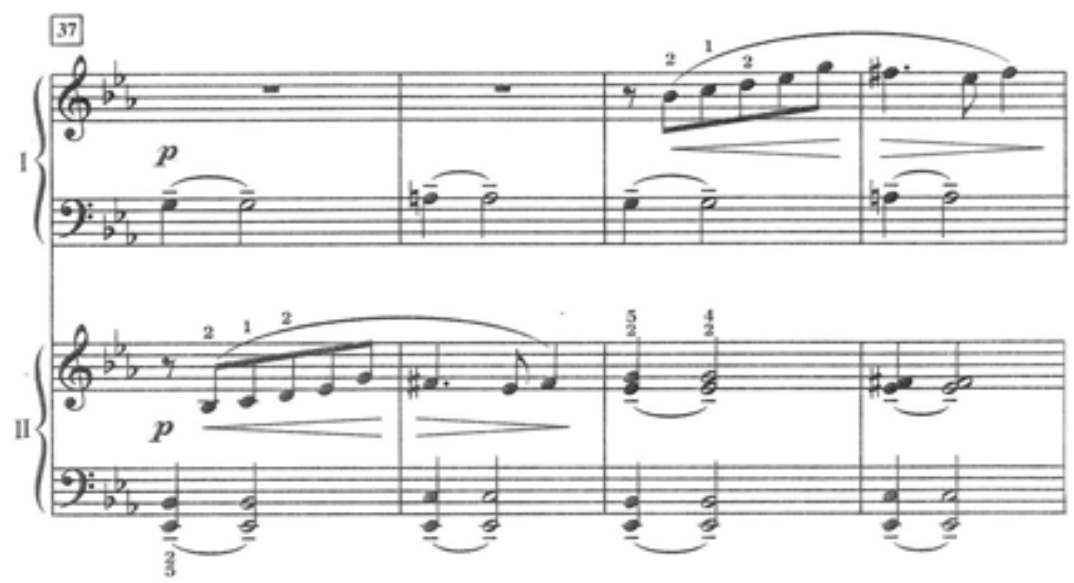

Example 27. Opening of the B theme, "Valse Triste" from Six Morceaux Op. 41 no. 2 by Glière, mm. 37-40 
Between mm. 57 and 60, a motive of the A theme reappears, followed by varied material from the B theme from mm. 61-63. Finally, in mm. 64-79, a complete statement of the A theme is accompanied by the scale-wise motive of the B theme, and then the last phrase of the A theme (accompanied by the B theme motive) is heard one final time (mm. 80-89). Although material from both A and B themes appears in different voices and in different piano parts, the balance should be adjusted according to the relative importance of material, as follows:

1. Material from theme A

2. Material from theme B

3. Bass line

4. Chords

When dealing with issues of balance, students should remember that a theme or motive will be heard and recognized more easily if it is performed with consistent phrasing and articulation. Both players should identify their cadences and breathe together when they are playing the same material. Observing the tenuto indications is important as well. To make the scale-wise B material flow smoothly without accents, the teacher should guide students to use more wrist motion. Also, singing will help the students shape each of the scale passages more effectively. Another practice suggestion might be saying/singing "2-3-4-5-6" for each eighth note to avoid having any unwanted accents. Finally, to help students hear all parts of the texture and make the appropriate adjustments to balance, phrasing and articulation, the teacher might recommend that they practice different pairs of voices together before playing all voices as written. 


\section{$\underline{\text { Pedaling }}$}

While pedaling can be very challenging when performing piano duets since one performer must pedal for both parts, pedaling when performing piano duos does not pose this challenge since each performer has control of his own pedal. On the other hand, two grand pianos played together can create a sound which is too blurry or too heavy if both performers over pedal. Using too much pedal may ruin the interpretation and beauty of the music. But, using too little pedal may not allow for proper phrasing or harmonic coloring. Therefore, both performers must always be alert and listen carefully to the sonority produced under different circumstances, such as in a different size room or with a different placement of the pianos. These variables will affect the sonority and should also affect the amount of pedal used. Furthermore, the amount of pedal used will vary widely depending on the style and musical period of the composition performed. In the discussion of Meter Changes, the use of una coda and half pedal were suggested when performing Ravel's "Petit Poucet” from his Ma Mère L'oye (see pages 42-44). The use of pedal will now be explored further in the following discussion of the Waltz Op. 39 no. 15 by Brahms.

Brahms's Waltz Op. 39 no. 15 is an excellent piece for the duo team to use when practicing how to pedal wisely. Even though some suggestions for performing this piece have already been provided in the discussion of Phrasing and Articulation (see pages 4749) the use of the pedal in this piece merits further discussion.

Sometimes different editors will indicate their own pedaling for a piece; however, students can often be more independent in developing their own interpretation (by using and honing their listening skills) if there are no editorial suggestions in the score. At the 
very least, teachers should recommend an edition where the editor distinguishes his suggestions from the composer's indications. As a general rule, elementary-level students are taught to change pedal when the harmony changes. In this piece, when the harmony changes within the measure (e.g., m. 7), students should change the pedal with the change of harmony. However, given the character, dynamic level, and performance medium for this piece, longer durations of the same harmony do not necessarily mean maintaining the same pedal for long periods of time. For example, although the harmony of the first two measures remains $A^{b}$ major, the build-up of sound and overtones produced by the pedals of two pianos requires that the pedals be cleared before the harmony changes. After experimenting with various pedaling schemes, this author suggests that when the same harmony remains in effect for one measure or longer, the performers should depress their pedals on beat one of the measure and should release them right on beat 3 (see Example 28).

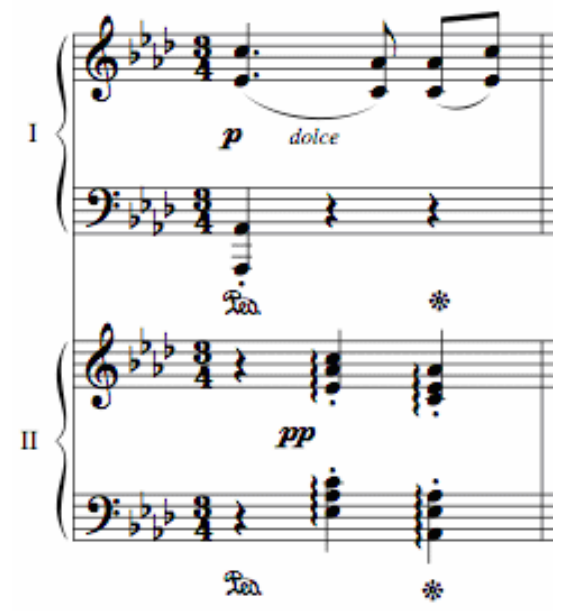

Example 28. Suggested pedaling, from Brahms's Waltz Op. 39 no. 15, m. 1 
While the pedals could be held for the entire measure, the sonority produced would be too heavy for the character of this waltz. Also, in order to project the two-note slur on beat 3, the Piano I performer can connect these notes with fingers alone (sometimes referred to as "finger pedal"). ${ }^{112}$

In measures such as $\mathrm{m} .32$, where the harmony changes in the Piano I part, that performer should change pedal for every single chord; even though the Piano II parts maintain the $\mathrm{D}^{\mathrm{b}}$ harmony for two beats, the present author suggests changing the pedal on each beat to avoid excessive build-up of sound (see Example 29).

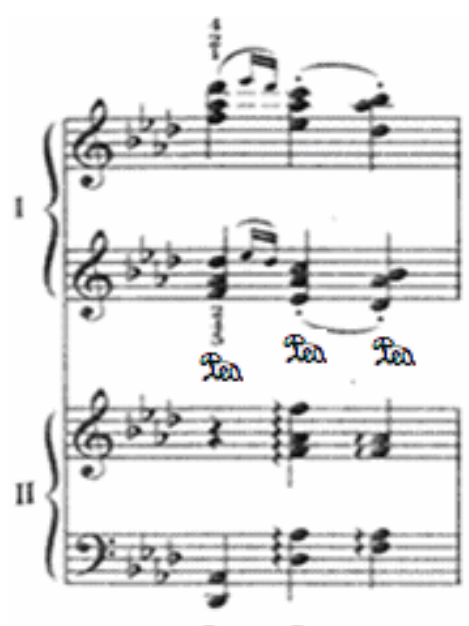

Lear tear teas

Example 29. Suggested pedaling from Brahms's Waltz Op. 39 no. 15, m. 32

Inexperienced pianists are often confused by staccato indications in passages that incorporate pedal (see staccato markings in Examples 27 and 28 above). The teacher should be sure that students observe these markings faithfully since the combination of a staccato articulation and use of the damper pedal produce a distinctive sound.

\footnotetext{
${ }^{112}$ If a student's hands are too small to observe the two-note slur in both the soprano and alto lines, he should at least observe it in the soprano line.
} 
The teacher should also make sure that young students do not overuse the pedal, which they often do when playing Romantic compositions. While this is important in all types of keyboard repertoire, it is especially critical when two pianos with two damper pedals are involved. This author recommends that the teacher let the duo-piano team experience and explore different options for pedaling. This will train them to be more sensitive to the different sonorities that can be produced by different pianos in different rooms, and to adjust their performance accordingly. In addition, further development of their listening skills will also be helpful when they perform solo music in different venues (e.g., a small practice room versus a big recital hall with an audience).

\section{Coordination of the ensemble (watching, signaling, breathing)}

Unlike solo playing, duo playing involves two different people who have different personalities, interpretations, and abilities. On the other hand, playing duos can develop one's teamwork as well as communication skills. Since these skills are important in many other areas of life, learning these skills at an early age is necessary and beneficial. Thus, assigning young intermediate students piano duos can not only develop their technical and musical skills, but can also build up the communication and collaboration skills needed to work with another performer (s) when playing other kinds of ensemble music.

Certainly, both performers should discuss issues such as phrasing, pedaling, articulation, dynamics, rhythm, and tempo before they rehearse a piano duo. However, watching, signaling, and breathing should also be discussed before starting to play. The large size of two grand pianos can often cause problems in coordinating the ensemble. While placing the two grand pianos side by side eases coordination difficulties for the 
two performers in terms of signaling and breathing, it also affects the sound; with this arrangement of instruments, the sound produced might not be as powerful as it should be, and/or the accompaniment may overshadow the melody line. Therefore, sometimes the performers will put the two grand pianos tail by tail so that the sound will be more centralized. Unfortunately, having the two music racks up may cause problems for the two performers in terms of watching and signaling to each other. This author has learned from experience that when working with young intermediate-level students (especially those of small stature), the preferred arrangement of instruments should still be putting the two pianos side by side. Even though the sound produced might not be as centralized as putting the two pianos tail by tail, students will feel more comfortable and secure, and will enjoy the ensemble experience more if they are able to see their partner easily during performance.

"Pavane de la Belle au bois dormant" from the Ma Mère L'oye by Ravel is an excellent piece to use when teaching young intermediate-level students to watch, signal, and breath with a duo partner. In terms of pitch and rhythm, this piece is not hard at all; in fact it is quite simple. However, in order to play this piece well, both the performers should pay close attention to the tone color, articulation, weight of every note, balance, breathing, dynamics, and phrase shaping in both parts. In order to accomplish this, communication between performers (e.g., watching, signaling, listening and responding to one's partner) is required during performance.

When a teacher assigns this piece to a young duo team, the first thing she should do is to be sure the students understand the title and the mood it suggests. Students should 
learn that a pavane is a "slow, processional type of dance" 113 and that "Pavane de la Belle au bois dormant" means "Sleeping Beauty's Dance." Not surprisingly, this is a very slow, quiet piece, with regular four-bar phrases. Even though the performers do not need to rush, it is quite a challenge for both players to articulate the first and last notes in each phrase with a soft, very sensitive touch which can create a sonority appropriate for this fairy tale about a sleeping beauty (see Example 30). Attention to sonority and tonal nuances is one of the main challenges in this piece.

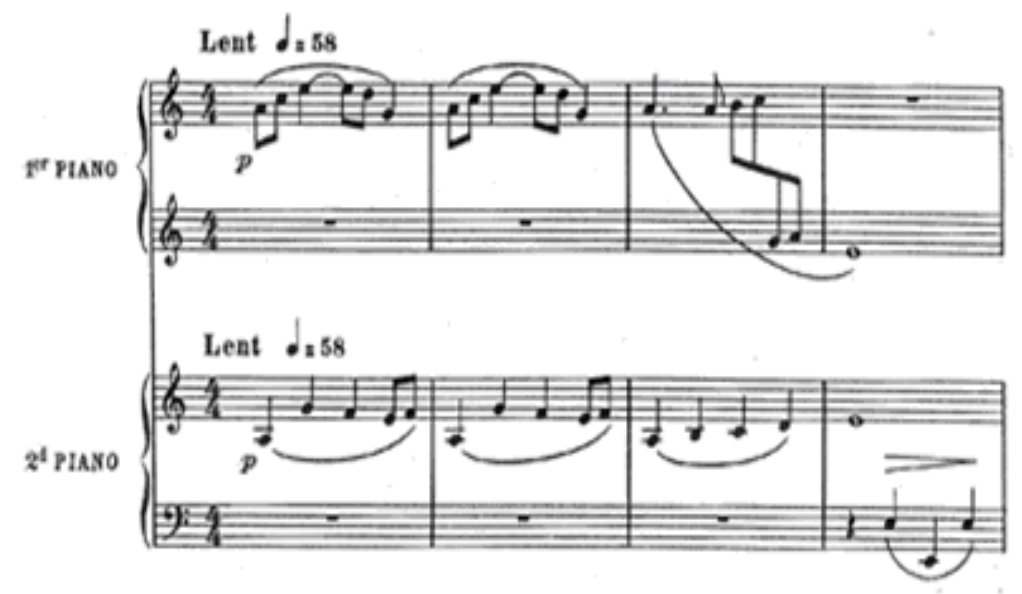

Example 30. Sensitive touch, "Pavane de la Belle au bois dormant" from Ravel's Ma Mère L'oye, mm. 1-4

Of course, the phrases must not only be played sensitively, but also precisely together. To help them acquire this ensemble skill, the teacher should suggest that both performers mark down in the score where they need to watch each other in order to begin and end each phrase exactly together. Teachers should suggest that both students get together to sing their parts together in the performance tempo before playing on the pianos. This will help them to identify where they should breathe between phrases.

${ }^{113}$ The Harvard Dictionary of Music, $4^{\text {th }}$ ed., s.v. "Pavana," by Lawrence H. Moe. 
Switching parts during rehearsal can also help each performer become familiar with the entire composition (rather than just his part).

With two different pianists playing together, both players need to figure out a way to signal each other so that they can articulate the first note exactly together and can lift their hands off the last note exactly together. When starting the piece, the Piano I performer should give the signal providing the pulse because he has the melody as well as the shortest rhythm values. While counting out loud allows the duo team to find a common tempo and begin together during a rehearsal, this is not an acceptable solution during a performance. Therefore, students should experiment with other signals such as taking a deep breath, nodding the head slightly, softly tapping on the key, or even lifting the wrist or finger as an upbeat in the desired tempo. Regarding the performance of rubato at phrase ends and the performance of the rallentando in the final measure, both players should communicate with each other in rehearsal, counting aloud as they play to determine the desired amount of tempo change. Conducting these passages and their tempo fluctuations can also help performers interpret them consistently. Finally, they should stop counting aloud and the performer with the shortest rhythm values (i.e., the Piano II performer in m. 20) or the performer with the main melodic material should illustrate the tempo change with the head or finger movements described above. Watching each other carefully is critical to a successful performance.

As noted above, creating appropriate tonal nuances and sonority for this fairy tale about a Sleeping Beauty is one of the main challenges of performing this piece. Careful pedaling also plays a critical role in achieving this sonority. Since this is a very slow, legato piece, both performers should keep changing pedal to avoid creating a sound 
which is too blurry and messy. In fact, the use/change of the pedal will not be identical for both performers. The Piano II performer should use full pedal and should change it on every beat in mm. 1-8. However, since the Piano I part has more notes involved (mm. 18), the performer should be very alert and change pedal as needed to avoid a blurry sound. Also, to maintain a legato and hazy sound, the Piano I performer should use a half pedal. Both performers reverse their uses of pedal when the rhythmic activity in their parts changes from mm. 9-16. In addition, to create a different tone color for phrases in the higher register marked $p p$ (i.e., mm. 5-8 and mm. 17-20), teachers may want to suggest that the students use the una coda pedal in these sections. Lastly, both performers should pay careful attention to pedaling in the last measure. Since both piano parts end with a fermata and a rest, both performers should watch each other and lift their hands and pedals together gradually. During rehearsals, the performers should experiment with different ways of pedaling in order to achieve a successful performance. Final decisions regarding pedaling should be made in the concert hall.

To create a successful ensemble, coordination and communication between players is essential. Young pianists should be encouraged to develop these skills as well as the other technical and musical skills and knowledge discussed in this chapter at an early age. Students cannot develop all of these skills in solo playing. Skills such as communication and coordination; matching a partner's phrasing and articulation; or adjusting one's dynamics or pedaling based on the musical composition as a whole (and not just on one's individual part) requires collaboration with a partner. This collaboration not only develops teamwork, but can also help students discover the joy of making music with others. Furthermore, skills developed in duo playing such as listening and blending 
can help improve solo playing. However, individual practice is also important. A useful way to practice, both individually as well as with one's partner, is to record the partner's part as well as the entire ensemble using a disklavier or other sequencing technology. Practicing one's part along with a recording of the partner's part can help one practice more effectively and accurately in terms of rhythm, balance, etc. This type of individual practice can lead to better collaboration between players when they rehearse together. Then, to be sure that ensemble and interpretive goals have been achieved, the duo team should record a performance of the entire work and then listen to it and critique it together.

Finally, duo-piano playing can not only lead to a greater familiarity with and appreciation of the keyboard repertoire, but can also offer students a chance to exchange ideas and learn from another musician (their partner), which can promote further development and exploration of different musical interpretations. 


\section{CHAPTER IV}

\section{SUMMARY, CONCLUSIONS, AND RECOMMENDATIONS FOR FURTHER RESEARCH}

\section{$\underline{\text { Summary }}$}

Given the importance of ensemble performance, pianists should begin to develop expertise in this area as early as possible. Duo piano playing is especially beneficial and accessible for young pianists since it helps develop collaborative skills without requiring knowledge and familiarity with other instruments. Furthermore, playing piano duos can heighten students' interest and enthusiasm for learning, can develop their technique and musicianship skills, and can help prepare them for study of more advanced solo and ensemble piano repertoire. In addition, playing duos can also help to establish some daily life skills that everybody should have such as personal responsibility, time management, self-discipline, objectivity, compromise and communication with peers.

The purpose of this study is to identify piano duo repertoire appropriate for the intermediate level of piano study, to highlight intermediate-level technical and musical skills that can be taught through the study of this repertoire, and to suggest instructional techniques and strategies that can be used when teaching these duos to developing students.

The following technique and musicianship skills are discussed in this study: 
1. Rhythm - Intermediate-level piano duos incorporating syncopation, different kinds of cross rhythms (various different triple against duple rhythms), and meter changes were found and discussed.

2. Phrasing and articulation - The analysis of piano duos highlights the need for intermediate piano students to learn how to delineate phrases (when composers did not include phrase markings in the score) and breathe together, as well as to develop skill in matching their partner's phrasing and articulation in order to achieve a unified interpretation. Furthermore, singing, conducting, reversing parts and using rubato to highlight phrase shaping were also discussed.

3. Dynamics - Since two grand pianos played together can produce and project great sonority as well as multiple layers and a wider range of dynamics, learning to control the pacing and balance of dynamic levels is critical to successful duopiano performance. The development of these skills and the relationship of dynamics to the structure of a piece were discussed.

4. Musical style - Intermediate-level duo repertoire composed during the Renaissance, Baroque, Classical, Romantic, and twentieth-century periods was identified and discussed. Skills and concepts related to the musical style of each period were highlighted for each piece.

5. Balance -The balance between pianos and within each piano part was discussed in terms of melody, bass line, chords, and doublings of voices. The importance of projecting each voice within the texture according to its relative importance was also stressed. 
6. Pedaling - Overuse of pedal can easily occur in duo playing. While final decisions regarding pedaling should take into account the size of the room and the placement of the two pianos, recommendations were offered for use of the damper and una corda pedals in selected duos.

7. Coordination of the ensemble - Duo-piano playing involves careful communication between the two players. Watching, signaling, listening, and responding are needed to achieve a successful performance. Even though the sound might not be as centralized, this author recommends that the pianos be placed side by side in order to facilitate communication between young, inexperienced duo performers. For the reader's convenience, complete reference citations for all of the pieces and collections that are discussed in this study are provided in Appendix A.

\section{$\underline{\text { Conclusions }}$}

The following conclusions may be drawn from this study:

1. Learning piano duos can motivate students to continue their piano study, can increase their communication ability and maturity in working with another player, and can present some unique challenges that are not encountered in solo playing (e.g., watching, signaling, breathing and listening to another person, and responding).

2. The examination and review of duo literature revealed that, despite the more limited repertoire of piano duos than piano duets, piano duos from the Renaissance through the twentieth century could be found to reinforce various 
skills and concepts at a level of advancement typically encountered at the intermediate level of piano study.

3. Practicing and performing piano duos hones listening ability since it requires listening to more parts simultaneously, performing within a wider dynamic range, and controlling sonority produced by two instruments. The simultaneous performance of two pianos creates greater challenges than solo performance in areas such as balance and pedaling.

4. Practicing with a partner can help students solve performance problems (e.g., tapping cross rhythms together to ensure accuracy, or suggesting imagery to one another to inspire interpretation). Furthermore, both students can learn from each other's ideas.

5. Learning and playing duo music will strengthen and improve performance and musicianship since duo performers not only need to hone their own part (in terms of technique and interpretation) but also need to combine it with that of their partner to create a unified performance of the composition as a whole.

6. Discussing difficulties related to phrasing, dynamics, and other aspects of interpretation with one's partner can help develop critical thinking and creativity.

7. A successful performance of piano duos (both on stage and in rehearsal) requires the development of flexibility and freedom not only to achieve spontaneity in performance, but also to be able to respond to your partner's inspiration and spontaneity in performance.

8. Pairing students correctly is a challenge for the teacher of intermediate students. There are several ways to create effective partnerships. A student with a weak 
rhythmic sense can be paired with another student who has a stronger rhythmic sense. Or, a talkative student can be paired with a student who does not like to waste time. Or, an uninspired student can be paired with someone who would like to lead the duo team.

\section{$\underline{\text { Recommendations for Further Research }}$}

The literature review and analysis of piano duos (in Chapters II and III respectively) suggest the following avenues for future research:

1. Future researchers should investigate the benefits of using piano duos in applied piano lessons at different levels of advancement. Even though other researchers have studied advanced piano duos, this research consists primarily of historical surveys and theoretical analyses.

2. Future researchers should investigate the benefits of teaching and performing arrangements and transcriptions for piano duo.

3. Future researchers should investigate the benefits of using piano duos to teach sight reading in partner lessons or in group piano classes.

4. Future researchers should investigate the benefits of teaching and performing intermediate-level chamber music which combines piano with another instrument(s).

5. Future researchers should investigate the benefits of having duo pianists participate in large, non-piano ensembles such as choirs, bands or orchestras. 


\section{APPENDIX A \\ TITLES, COMPOSERS, AND PUBLICATION INFORMATION}

Arensky, Anton. "Elegie - Canon At The Fifth," Suite In Canon-Form Op. 65. Edited by Mrs. Crosby Adams. New York: G. Schirmer, Inc, 1924, 11-13.

. "Intermezzo - Canon At The Seventh," Suite In Canon-Form Op. 65. Edited by Mrs. Crosby Adams. New York: G. Schirmer, Inc, 1924, 16-17.

Bach, Carl Philipp Emanuel. "Four Little Duets For Two Keyboards Wotq 115, No. 2." In Essential Two-Piano Repertoire: 20 Late Intermediate/Early Avanced Selections in Their Original Form Baroque to Modern, ed.Lucy Mauro and Scott Beard, 7-9. California: Alfred Publishing Co. Inc., 2004.

Bartók, Béla. "New Hungarian Folk Song," Seven Pieces from the Mikrokosmos. U.S.A.: Boosey \& Hawkes, Ltd., 1947, 18-19.

Bennett, Richard Rodney. "Country Blues," Four Piece Suites. London: Novello Publishing Limited, 1984, 12-18.

Brahms, Johannes. Walzer Für Klavier Zu 4 Händen Opus. 39 no. 11. Frankfurt, London, and New York: C. E. Peters, 1970, 4-5.

. Walzer Für Klavier Zu 4 Händen Opus. 39 no. 15. Frankfurt, London, and New York: C. E. Peters, 1970, 8-9.

Casella, Alfredo. "Marcietta," Pupazzetti - 5 Musiche Per Marionette. London: J. \& W. Chester, Ltd., 1921, 1-5.

Clementi, Muzio. "Sonata in $\mathrm{B}^{\mathrm{b}}$ major Op. 12," Two Sonatas. New York: G. Schirmer, $1929,16-24$.

Couperin, François. La Létiville. London: Oxford University Press, 1934, 2-3.

Farnaby, Giles. "For Two Virginals," Fitzwilliam Virginal Book Vol. 2 
Gliere, Reinhold. "Valse Triste," Six Morceaux Op. 41. In Essential Two-Piano Repertoire:20 Late Intermediate/Early Avanced Selections in Their Original Form Baroque to Modern, ed. by Lucy Mauro and Scott Beard, 123-128. California: Alfred Publisher Co. Inc., 2004.

Gurlitt, Cornelius. Eight Melodious Pieces, Op. 174 no. 5. U.S.A.: Schirmer's Library Of Musical Classics, 1980-1999, 10-11.

Luening, Otto. The Bells of Bellagio. New York: C. F. Peters Corporation, 1973, 2-5.

Ravel, Maurice. "Petit Poucet," Ma Mére L'oye. Paris: Durand \& C 5.

. "Pavane de la Belle au bois dormant," Ma Mére L'oye. Paris: Durand \& C Editeurs, 1910, 2-3. 


\title{
APPENDIX B
}

\author{
DISCOGRAPHY ${ }^{114}$
}

A Celebration of Duo-Piano Music, Madeleine Forte and Del Parkinson, (United States: Roméo Records, 2006), CD audio.

Includes performances of the following repertoire:

España /; Emanuel Chabrier; --; Rapsodia española /; Isaac Albéniz; --; Spanish rhapsody /; Franz Liszt ; arr. Ferrucio Busoni; --; Andalusian dances; Ritmo; Sentimiento; Gracia (El vito); /; Manuel Infante --; Rhapsodie espagnole.; Prélude à la nuit; Malagueña; Habanera; Feria; /; Maurice Ravel --; Carmen fantasy /; Georges Bizet ; arr. Abram Chasins; --; Danse espagnole no. 1 (La vida breve) /; Manuel de Falla; Variations on a theme by Beethoven, op. 35 /; Camille Saint-Saëns;--; En blanc et noir /; Claude Debussy;--; La valse /; M. Ravel; --; Concerto for two pianos /; Francis Poulenc; --; Valse-musette /; F. Poulenc; Suite no. 2, op. 17 /; Sergei Rachmaninoff; --; Six pieces /; Reinhold Glière; --; Suite, op. 15/; Anton Arensky; --; Fantastic waltz (from Three pieces) /; Aram Khatchaturian; --; Fantasy, op. 5 /; S. Rachmaninoff.

Audrey Hepburn's Enchanted Tales, Audrey Hepburn and Mary Sheldon, (Beverly Hills, CA: Dove Audio, 1993), cassette.

Includes performances of the following repertoire:

Ma mère l'oye: Sleeping beauty -- Tom Thumb -- Beauty \& the beast -- Laidronette, Empress of the Pagodes

\section{Bradshaw \& Buono: Piano Duo, David Bradshaw and Cosmo Buono, (New York: Connoisseur Society, 1988), CD audio.}

Includes performances of the following repertoire:

Prelude to the afternoon of a faun (trans. by Ravel); Petite suite; Sacred and profane dances (trans. by Debussy) / Debussy -- Mother Goose; Frontispiece, for two pianos, five hands / Ravel -- The poisoned fountain / Arnold Bax -- Pupazzetti / Alfredo Casella .

Children’s Corner, Duo Tal \& Groethuysen, (Germany: Sony Music Entertainment, 202, 2001), CD audio.

Includes performances of the following repertoire:

15 portraits d'enfants d'auguste renoir / Jean Francaix -- Sei piccoli pezzi / Ottorino Resphighi-- Spiel um ein kinderlied / Walter Gieseking-- Jeux d'enfants op. 22 / Georges Bizet -- 3 kinderszenen / Josef Dichler - Pupazzetti. 5 pezzi facili op. 27 / Alfredo Casella.

${ }^{114}$ This discography lists recordings of pieces discussed in this study. 
Cinderella Suite, Martha Argerich and Mikhail Pletnev, (Hamburg, Germany: Digital Stereo, 2004), CD audio.

Includes performances of the following repertoire:

Cinderella: suite from the ballet, op. 87 / Serge Prokofiev; transcribed for 2 pianos by Mikhail Pletnev -Ma mère l'oye : 5 pieces for children for piano, four hands / Maurice Ravel .

Colori E Virtuosismo Del '900 Italiano: Timbres and Virtuosity in $20^{\text {th }}$ Century Italian Music, Sebastiano Brusco and Marco Scolastra, (Austria: Phonix Classics, 1998), CD audio.

Includes performances of the following repertoire:

Fuga sul canto popolare $=\mathrm{O}$ du lieber Augustin; Duettino concertante su un tema di Mozart; /; Ferruccio Busoni --; Pagine di guerra = pages of war; Pupazzetti; Fox trot; /; Alfredo Casella --; Sei piccoli pezzi; /; Ottorino Respighi --; Sicilana e marcia;/; Goffredo Petrassi --; Dialogo II fra due pianoforti; /; Gian Francesco Malipiero.

\section{Duo Campion-Vachon: Piano á quatre mains, Duo Campion-Vachon, (Quebec: ADDA} distribution, 1991), CD audio.

Includes performances of the following repertoire:

Trois pièces faciles pour piano à quatre mains ; Cinq pièces faciles pour piano à quatre mains / Igor Stravinsky -- Pupazzetti, op. 27 ; Pagine di guerra, op. 25 / Alfredo Casella -- Ma mère l'oye / Maurice Ravel -- Dolly / Gabriel Fauré.

Duo Pianistico: Dirani - Amelotti, Paolo Dirani and Ferruccio Amelotti, (Italy: Fonè, 1990), CD audio.

Includes performances of the following repertoire:

Pensieri sull'opera "Un ballo in maschera" op. 8 / G. Martucci -- Sei piccoli pezzi / O. Respighi -Pupazzetti op. 27; Pagine de guerra op. 25 / A. Casella -- Pause del silenzio / G.F. Malipiero .

French Music for Two Pianos and for Piano, Four Hands, Geneviève Joy and Jacqueline Robin-Bonneau, (New York: Musical Heritage Society, 1968), LP recording.

Includes performances of the following repertoire:

Trois valses romantiques. Très vite et impétuesement ; Mouvement modéré de valse ; Animé / Emmanuel Chabrier -- Habañera / Maurice Ravel -- Six danses exotiques. Pambihe ; Baiao ; Nube gris ; Merenge ;

Samba lente ; Mambo / Jean Francaix -- En blanc et noir; Lindaraja / Claude Debussy.; French piano duets. Dolly : op. 56. Berceuse ; Mi-a-ou ; Jardin de Dolly ; Kitty valse ; Tendresse ; Pas espagnol / Gabriel Fauré -- Six épigraphes antiques. Pour invoquer Pan, dieu du vent d'été ; Pour un tombeau sans nom ; Pour que la lut soit propice ; Pour la danseuse aux crotales ; Pour l'égyptienne ; Pour remercier la pluie au matin /

Claude Debussy -- Ma Mère l'Oye / Maurice Ravel.

French Piano Duets, Laurence Fromentin, Dominique Plancade, (New York: EMI Classics, 1998), CD audio.

Includes performances of the following repertoire:

Sonate / Francis Poulenc -- Petite suite / Claude Debussy -- Ma mère l'oye / Maurice Ravel -- Dolly suite : op. 56 / Gabriel Fauré -- Jeux d'enfants / Georges Bizet. 
Gaspard De La Nuit. Valses Nobles Et Sentimentales. Ma Mére L'oye, Emanuel Ax and Yoko Nozaki, (RCA Red Seal, 1978), LP recording.

Includes performances of the following repertoire:

Ravel: Valses nobles et sentimentales and Ma mère l'oye (Piano duet).

Giles Farnaby's Dream: Pieces Pour Clavier, Pierre Hantaï and Elisabeth Joye, (France: ADDA; New York: Dist. by Qualiton Imports, 1990), CD audio.

Includes performances of the following repertoire:

For two virginals (with Elisabeth Joye, harpsichord) -- Muscadin -- Fantasia (M.B. no 5) -- Meridian alman -- Mal Sims -- Alman (M.B. no 22) -- Rosseter's galliard -- Wooddy-cock -- A maske (M.B. no 33) -Pawles wharfe -- The old spagnioletta -- Fantasia (M.B. 12) -- His humour -- A maske (M.B. no 31) -- The king's hunt -- Fantasia (M.B. no 7) -- A gigge -- Galliarda -- Tell mee Daphne -- Spagnioletta -- Fantasia (M.B. no 10) -- A maske (M.B. no 32) -- Alman, M.B. no 23 / Johnson ; set by Farnaby -- Fantasia (M.B. no 6) -- Pavana / Johnson ; set by Farnaby -- Why aske you -- Giles Farnabys dreame -- Quodling's delight -- Lachrymae pavan / Dowland ; set by Farnaby -- A toye.

Jeux d'enfants, Katia Labèque and Marielle Labèque, (West Germany: Philips, 1987), CD audio.

Includes performances of the following repertoire:

Dolly : op. 56 / Gabriel Fauré. Ma mère l'oye : 5 pièces enfantines / Maurice Ravel.

L'apothéose De Lulli, William Christie and Christophe Rousset, (Arles: Harmonia Mundi France, 1988, 1987), CD audio.

Includes performances of the following repertoire:

Couperin, François: Apothéose de Lully. Parnasse, and Pièces de clavecin,; 2e-3e livre.; Selections.

La Paix Du Parnasse, Lucy Carolan and John Kichen, (Edinburgh: Delphian, 2003), CD audio.

Includes performances of the following repertoire:

Allemande à deux clavecins : 9e ordre -- L'Evaporée -- L'amour au Berceau -- Muséte de choisi -- Muséte de taverni : 15e ordre - La Paix du parnasse -- Le Rossignol en amour - La Julliet -- Le Carillon de Cithére -- Le Petit-Rien : 14e ordre -- Concert Royal no. 3 in A -- Grande Ritournéle(Concert Royal no. 8 -- Le Drôle de Corps - La Distraite - La Létiville : 16e ordre -- Menuet en Trio (Concert Royal no. 1) - La Steinquerque.

Music for Two Harpsichords, Igor Kipnis and Thurston Dart, (Columbia M 31240, 1972), LP recording.

Includes performances of the following repertoire:

Suite à deux clavecins in C minor, G.F. Handel.--Fancy, for two to play, T. Tomkins.--Ut re my fa sol la, W. Byrs.--For two virginals, G. Farnaby.--Suite in G minor, G. Le Roux.--Allemande à deux clavecins. La julliet. La Létiville. Muséte de choisi. Muséte de taverni. F. Couperin.--Sonata in C major for four hands, K. 19d. Fugue in C minor, K. 426. W.A. Mozart. 
Music for Two Pianos, Liselotte Gierth and Gerd Lohmeyer, (New York: Mace, 1960), LP recording.

Includes performances of the following repertoire:

Sonata no. 1, B-major, by Clementi.--Sonata, D-major [KV448] by Mozart.--Scaramouche, by Milhaud.-Sonata, by Poulenc.--Seven pieces from the Mikrokosmos, by Bartók.--Variations on a theme from

Paganini, by Lutoslawski.

Piano Works: Klavierwerke, Pascal Rogé and Denise-Françoise Rogé, (London: Digital Stereo, 1994), CD audio.

Includes performances of the following repertoire:

Gaspard de la nuit -- Valses nobles et sentimentales -- Jeux d'eau -- Miroirs -- Sonatine -- Le tombeau de

Couperin -- Prélude -- Menuet sur le nom d'Haydn -- À la manière de Borodine -- Menuet antique -- Pavane pour une infante défunte -- À la manière de Chabrier -- Ma mère l'Oye.

Pièces Pour 2 Pianos, Ruth Laredo and Jacques Rouvier, (Japan: Denon, 1986), CD audio.

Includes of the following repertoire:

Ravel: Bolero(orchestra); Ma mère l'oye (Piano duet); Sites auriculaires; Frontispice; Valse.

Ravel/Debussy Klaviermusik zu vier Händen, Alfons Kontarsky and Aloys Kontarsky, (Deutsche Grammophon, 1973), LP recording.

Includes performances of the following repertoire:

Debussy, C. En blanc et noir.--Ravel, M. Ma mère l'oye.--Debussy, C. Petite suite. Lindaraja. Cortège et air de danse. Ballade.--Ravel, M. Rapsodie espagnole. Debussy, C. Six épigraphes antiques. Symphonie en si mineur. Marche écossaise. Prélude à l'après-midi d'un faune.--Ravel, M. Entre cloches. Frontispice.

Respighi, Busoni, Casella, Hecto Moreno and Norbeto Capelli, (Genoa, Italy: Dynamic, 1992), CD audio.

Includes performances of the following repertoire:

Suite della tabacchiera / Ottorino Respighi -- Fontane di Roma. La fontana di Valle Giulia all'alba ; La fontana del Tritone al mattino ; La fontana di Trevi al meriggio ; La fontana di Villa Medici al tramonto /

Respighi -- Sei pezzi per bambini. Romanza ; Canto di caccia siciliano ; Canzone armena ; Natale, Natale! ; Cantilena scozzese ; Piccoli highlanders / Respighi -- Finnländische Volksweisen : op. 27 / Ferruccio Busoni -- Pupazzetti : op. 27. Marcetta ; Berceuse ; Serenata ; Notturnino ; Polka / Alfredo Casella-- Fox trot /Casella-- Pagine di guerra. In [Nel?] Belgio : sfilata d'artiglieria pesante tedesca; In Francia : davanti alle rovine della cattedrale di Reims ; In Russia : carica di cavalleria cosacca ; In Alsazia : croci di legno ; Nell'Adriatico : corazzate italiane in crociera.

Clementi: Sonata in $B^{b}$, Op. 46. Sonata in $B^{b}$, Op. 12, Joan Yarbrough and Robert Cowan, 1976, ORS 76232, LP recording.

Includes performances of the following repertoire:

Clementi: Sonata in $\mathrm{B}^{\mathrm{b}}$, Op. 46 . Sonata in B ${ }^{\mathrm{b}}$, Op. 12 
The Complete Piano Music for Maurice Ravel, Robert Casadesus and Gaby Casadesus, (New York: Sony Classical, 1998), CD audio.

Includes performances of the following repertoire:

Pavane pour une infante défunte -- A la manière de Chabrier : paraphrase sur un air de Gounod, Faust, Act II -- A la manière de Borodine : valse -- Sonatine -- Miroirs -- Ma mère l'oye -- Habanera from Sites auriculaires -- Jeux d'eau -- Prélude in A minor -- Menuet sur le nom d'Haydn -- Berceuse sur le nom de Gabriel Fauré -- Le tombeau de Couperin -- Valses nobles et sentimentales -- Menuet antique -- Gaspard de la nuit -- Piano concerto for the left hand.

The Complete Works for Ravel's Solo Piano, Philippe Entremont and Dennis Lee, (Columbia, D3M 33311, 1975), CD audio.

Includes performances of the following repertoire:

Pavanne pour une Infante défunte.--A la manieère de Chabrier.--A la manière de Borodine.--Sonatine.-Miroirs.--Ma mère l'oye (with Dennis Lee, piano).--Habañera (with Dennis Lee, piano).--Jeux d'eau.-Gaspard de la nuit.--Menuet antique.--Le tombeau de Couperin.--Valses nobles et sentimentales.--Prelude in A minor.--Menuet sur le nom d'Haydn.

The Fitzwilliam Virginal Book, Byron Schenkman and Maxine Eilander, (Louisiano: Centaur, 2003), CD audio.

Includes performances of the following repertoire:

O mistris myne / William Byrd -- Barafostus' dreame / anonymous -- Jhonson's medley / Edward Johnson - Pavana (CLIII) and galiarda (CLIV) / Thomas Morley -- Pavana (XIII) / John Bull -- Praeludium toccata / Jan Pieterszon Sweelinck -- Worster braules / Thomas Tomkins -- Callino casturame / William Byrd -Amarilli di Julio Romano ; Bon jour mon cueur di Orlando ; Galliardo (LXXXVII) / Peter Philips -- The old spagnoletta ; The L. Zouches maske / Giles Farnaby -- Pavana and galiarda / Thomas Warrock -Praeludium (XLIII) / John Bull -- Pakington's pownde / anonymous -- Heaven and earth / attrib[uted to] Francis Tregian -- Pavana lachrymae / Byrd -- Toccata / Giovanni Picchi -- For two virginals / Farnaby.

The Harpsichord \& Its History, Laurence Boulay and Robert Veyron-Lacroix, (New York: Musical Heritage Society, 1971), LP recording.

Includes performances of the following repertoire:

Canzona a 4 : "La Rolanda" / Claudio Merulo -- Toccata / Girolamo Frescobaldi -- French coranto /

William Byrd - The new Sa-hoo / Giles Farnaby - The Duchesse of Brunswick's toye / John Bull - The fall of the leafe / Martin Peerson -- A toye / Giles Farnaby -- Suite in F major ; Tombeau de Mr. de Blancrocher / Louis Couperin -- Arie / Bernardo Pasquini -- La gémissante / Jena-François Dandrieu -- La letiville ; Musette de Taverni / François Couperin -- Tombeau de Mr. de Blacheroche / Johann Jakob Froberger -Prélude ; Sarabande ; Gavotte : [from Pièces de clavecin (1706)] / Jean-Philippe Rameau -- Le carillon de cithère / François Couperin -- Carillons pour les heures du jour et de la nuit / Maurice Ohana -- Prelude and fugue in E-flat minor / Johann Sebastian Bach.

The Legacy of Maria Yudina Vol. 2, Maria Yudina and Mariana Drozdova, (Vista Vera: VVCD-00070, 2004), CD audio.

Includes performances of the following repertoire:

Sonata op. 59 / Ernst Krenek -- Sonata C-dur (1924) ; Serenade for piano A dur / Igor Stravinsky -- 8 pieces of solo piano music Microcosm. No. 128 : Peasant dance ; No. 132 : Major seconds ; No. 137 : Unison ; No. 142 : From the diary of a fly ; No. 144 : Minor seconds, major sevenths ; No. 145 : Chromatic 
invention (for two pianos) ; No. 146 : Ostinato ; No. 149 : Bulgarian rhythm (no. 2) / Béla Bartók -- Sonata for two piano (1942) / Paul Hindemith.

The Two Piano Artistry of Morley and Gearhart Rediscovered, Virginia Morley and Livingston Gearhart, (Delaware Water Gap, PA: Omnisound, N-1017, 1978), LP recording.

Includes performances of the following repertoire:

Sailor's dance from "The red poppy" / Gliere --Valse / Arensky --Concerto in F ; finale / Gershwin --Eight waltzes, op. 39 / Brahms --Waltzes from "Der Rosenkavalier" / R. Strauss --Piece en forme de Habanera / Ravel --Dance of fear from "El amor Brujo" / de Falla --Three blind mice / arr. Gearhart --All the things you are / Kern --I got rhythm / Gershwin --Stardust / Carmichael --The love for three oranges ; March op. 33 / Prokofief. 


\section{SELECTED BIBLIOGRAPY}

\section{$\underline{\text { Books }}$}

Albergo, Cathy, and Reid Alexander. Intermediate Piano Repertoire: A Guide for Teaching, $4^{\text {th }}$ ed. Canada: The Frederick Harris Music Co., Limited, 2000.

Chang, Frederic Ming, and Albert Faurot. Team Piano Repertoire: A Manual of Music for Multiple Players at One or More Pianos. New Jersey: The Scarecrow Inc, 1976.

Couperin, François. L'art De Toucher Le Clavecin. Translated and edited by Margery Halford. New York: Alfred Publishing Co., Inc., 1974

Ferguson, Howard. Keyboard Duets from the $16^{\text {th }}$ to the $20^{\text {th }}$ Century for One and Two Pianos: An Introduction. New York: Oxford University Press, 1995.

Friskin, James, and Irwin Freundlich. Music for the Piano: A Handbook of Concert and Teaching Material from 1580 to 1952. New York: Dover Publication, Inc., 1973.

Hinson, Maurice. Music for More Than One Piano: An Annotated Guide. Bloomington: Indiana University Press, 2001.

Kamien, Roger. Music An Appreciation, 4th ed. U.S.A.: McGraw-Hill, Inc., 1992.

Mauro, Lucu, and Scott Beard. ESSENTIAL TWO-PIANO REPERTOIRE: 20 Late Intermediate/Early Advanced Selections in Their Original Form Baroque to Modern. Van Nuys, CA: Alfred Pub. Co., 2004.

Maxwell, Carolyn. Maxwell Music Evaluation Notebook Ensemble Piano Literature. U.S.A.: Colorado, 1983.

Moldenhauer, Hans. Duo-Pianism. Chicago: Chicago Musical College Press, 1950.

Weeks, Marcus. Music: A Crash Course. New York: Watson-Guptill Publications, 1999.

\section{Theses and Dissertations}

Bridenthal, Dorothy. "A Critical Evaluation of Two-piano Music Available in American Publication.” M.M. thesis, North Texas State Teachers College, 1945. 
Cutting, Sister St. Cecilia. "Two-Piano Music for High School Students." M.M. thesis, University of Rochester, 1953.

Jeter, Eulalie Wilson. "The Study, Analysis and Performance of Selected Original Twopiano Music of Contemporary American Composers." Ed.D. diss., Columbia University, 1978.

Leech, William Crandall. "Music For Two Pianos.” M.M. thesis, University of Kansas, 1941.

McRobert, Gary Keith. "An Annotated Catalog of Original Two-Piano Literature 19501970.” M.A. thesis, California State University at Long Beach, 1973.

Neville, Ruth A. "The Study, Performance, and Recording of Selected Twentieth Century Repertoire for Multiple Keyboards." Ph.D. diss., University of California, San Diego, 1992.

Sloan, Chikako. "Comparison of Duo-piano Performance and Solo-piano Performance." M.M. thesis, The Ball State University, 1986.

Turrill, Pauline Venable. "The Two-Piano Idiom: An Analysis and Evaluation.” M.A. thesis, University of California, 1951.

\section{$\underline{\text { Articles }}$}

Duncan, Clyde. "Teaching Duo-Pianism.” Clavier 6, no. 2 (Feb. 1967): 20-21.

Hughes, Walden. "Music for Multiple Pianos During the Past 400 Years." Clavier 42, no. 5 (May/June 2003): 21-25.

Lhévinne, Joseph, and Rosina Lhévinne. "Four Hands that Play as Two..." Etude 51 (Dec 1933): 809-810.

Luboshutz, Pierre, and Genia Nemenoff. "The Art of Piano Ensemble." Etude 69 (Jan 1941): 5, 58 .

McCarthy, Margaret W.. "Two-Piano Music Around Beethoven's Time: Its Significance for the College Teacher." College Music Symposium 17, no. 2 (Fall 1977): 131143. 